\title{
LOS ESTADOS DE EXCEPCIÓN Y LAS SITUACIONES QUE HABILITAN SU DECLARACIÓN. UN ESTUDIO DESDE EL DERECHO COMPARADO
}

\section{Juan Santiago Ylarri}

Instituto de Investigaciones Jurídicas y Sociales "Ambrosio L. Gioja", Universidad de Buenos Aires

juan@ylarri.com.ar

Recibido: $16 / 04 / 2020$

Aceptado: 02/06/2020

\begin{abstract}
Resumen
Las constituciones suelen incluir ciertos institutos de excepción a los efectos de hacer frente a distintas emergencias. Uno de los requisitos de validez de esas normas de emergencia es que efectivamente exista una situación de emergencia. El presente trabajo tiene por objeto estudiar la regulación del mencionado requisito en diversos textos constitucionales, en particular de América Latina, Europa y Estados Unidos, y en dos tratados internacionales que tienen jerarquía constitucional en Argentina. Al respecto, debe destacarse la importancia de que el órgano que declare la emergencia justifique la existencia de la circunstancia fáctica excepcional. A su vez, que exista una relación de adecuación entre la declaración y las concretas medidas adoptadas. Finalmente, que se asegure un adecuado control de constitucionalidad.
\end{abstract}

Palabras clave: estado de excepción, declaración de emergencia, situación de emergencia, control de constitucionalidad.

\section{States of exception and the situations that enable their declaration. A study from comparative law}

\begin{abstract}
Constitutions usually include certain exceptional institutes in order to face different emergencies. One of the validity requirements of these emergency regulations is the actual existence of a state of emergency. The purpose of this work is to study the regulation of the mentioned requirement in various constitutional texts, particularly in Latin America, Europe and the United States, and in two international treaties that have constitutional hierarchy in Argentina. In
\end{abstract}


this regard, it should be stressed the importance that the branch of government that declares the emergency justifies the existence of the exceptional factual circumstance. Also, that there is an adequacy relationship between the declaration of emergency and the specific measures adopted. Finally, that an adequate judicial review is ensured.

Key words: state of emergency, declaration of emergency, emergency situation, judicial review.

\section{Introducción}

Las constituciones suelen incluir en sus disposiciones diversos institutos de excepción. Al respecto, podría hacerse una serie de preguntas acerca del modo en el que los textos constitucionales abordan la cuestión: ¿a quién le corresponde declarar la emergencia? ¿Se establecen limitaciones temporales a esos institutos de excepción a pesar de que pueda ser difícil determinar a priori el tiempo que dure una emergencia? ¿Tienen los poderes públicos el deber de motivar la efectiva existencia de la circunstancia fáctica excepcional? ¿Puede controlarse jurisdiccionalmente la constitucionalidad de la declaración de emergencia?

El presente trabajo pretende responder a estas y otras preguntas a la luz de las diversas prescripciones constitucionales, así como en ciertos tratados internacionales. En primer lugar, se estudiará el tratamiento de la cuestión en la Convención Americana sobre Derechos Humanos y en el Pacto Internacional de Derechos Civiles y Políticos. Seguidamente, se analizarán los casos de diversos países latinoamericanos, en particular de Argentina, Bolivia, Brasil, Chile, Colombia, Ecuador, México, Paraguay, Perú, Uruguay y Venezuela. A su vez, se prestará particular importancia a la Constitución de Estados Unidos. Finalmente, del continente europeo se estudiarán los textos constitucionales de Alemania, España, Francia e Italia. Desde ya, no analizaré en detalle cada uno de los supuestos, lo que excedería los objetivos y la extensión de este trabajo; me limitaré a analizar los textos constitucionales y a recoger el modo en el que los diferentes institutos fueron regulados. Sin perjuicio de ello, estudiaré con mayor profundidad el caso de Estados Unidos, cuyo modelo constitucional fue seguido por nuestro país.

\section{Los institutos de excepción y las situaciones que habilitan su declaración}

En el derecho constitucional cabe distinguir las situaciones de normalidad y las situaciones de excepción. En efecto, como lo ha destacado el jurista español Cruz Villalón (1984, p. 17), la constitución configura un determinado proyecto 
en relación con una situación considerada normal y previsible. Sin embargo, aquella norma puede verse súbitamente confrontada con una situación distinta, no prevista, por lo que la constitución puede encontrarse en una situación de no poder asegurar su propia eficacia. De esta situación deriva la distinción entre situaciones de normalidad y situaciones de excepción, o entre circunstancias ordinarias y circunstancias extraordinarias. Por lo tanto, podría decirse que en aquellas circunstancias se vería superada la capacidad normativa de la constitución, imponiéndose la "fuerza normativa de lo fáctico".

Del mismo modo, en relación con esta distinción entre circunstancias ordinarias y extraordinarias, García Pelayo (1999, pp. 162-163) destaca que el Estado de derecho se rige a través de una estructura jurídica que tiene una vigencia condicionada por la normalidad de su cumplimiento, por el orden de la sociedad a la que se aplica, por la realización espontánea en la mayoría de los casos de la conducta fijada como típica por la ley y, finalmente, por la permanencia de la situación sobre la que se estableció. Pero puede ocurrir que estos supuestos no se configuren, por lo que se estaría ante un caso excepcional al que no se le puede aplicar la regla general y que requiere, por lo tanto, medidas excepcionales. Sin embargo, el autor aclara que para que se trate de un caso excepcional

se requiere que la nueva situación tenga realmente un carácter anormal y, por consiguiente que sea limitada en el tiempo, pues, en caso contrario, nos encontramos ante un cambio general de supuestos que no engendra un derecho excepcional por su naturaleza y por el tiempo de su duración, sino un nuevo Derecho general. (García Pelayo, 1999, pp. 163)

Sin embargo, para evitar que se imponga la referida fuerza normativa de lo fáctico, la constitución puede inclinarse, como respuesta frente a aquella situación de crisis, por incorporar a su ordenamiento un modo alternativo de organización del poder que supone la negación temporal del orden constitucional en principio previsto, pero la cual tiene al menos dos ventajas. Por un lado, mantiene la eficacia formal de la constitución como constitución "alternativa" de emergencia, evitando la imposición de la fuerza normativa de lo fáctico. Por otro lado, facilita la vuelta ordenada a la constitución ordinaria o "legítima”. De este modo, destaca Cruz Villalón (1984, pp. 18-19), este derecho de excepción funciona como una garantía de la constitución ante las situaciones de crisis, aunque posee un peculiar problema: es una garantía que funciona como una suspensión temporal de ciertas prescripciones constitucionales. Sin 
embargo, el alcance de la problemática difiere en función de la naturaleza de la crisis de la que se trate. Pero, en todos los casos, adquiere toda su fuerza el viejo principio salus publica suprema lex. ${ }^{1}$

Así, se ha sostenido que la necesidad constituye el nexo jurídico entre un elemento fáctico y otro teleológico, facultando a los poderes públicos para adoptar las medidas indispensables en orden a la realización de un concreto fin amenazado por una situación fáctica determinada. A su vez, se ha precisado que a fin de ofrecer una causa de justificación, la necesidad puede operar de dos formas: a través de normas escritas, como, por ejemplo, el derecho de excepción, o bien directamente como un principio general del derecho que sirve como cláusula de cierre o "válvula de escape" ante supuestos de imprevisión normativa (Álvarez García, 1996, p. 47). ${ }^{2}$

En nuestro ámbito, Sagüés, analizando las relaciones entre el derecho constitucional y el derecho de necesidad, considera a la necesidad como opción constitucional, por lo que

la necesidad y la emergencia deben resolverse agotando al máximo todos los recursos que la Constitución contempla, instrumentándolos incluso de modo peculiar para encarar la situación de necesidad, con modalidades que no serían aceptables en épocas de normalidad, pero que sí se "constitucionalizan" en períodos de emergencia. (Sagüés, 1990, p. 1036)

Sin embargo, el autor afirma que en aquellos supuestos hay que tener en cuenta el "principio de restrictividad", es decir, que el derecho de necesidad solo puede afectar las reglas constitucionales en la medida indispensable para enfrentar la situación de necesidad (Sagüés, 1990, p. 1036; 2016, p. 57).

1 El derecho de excepción, lejos de ser una cuestión novedosa, encuentra sus primeros antecedentes en la dictadura constitucional en la república romana. Ha tenido también un desarrollo teórico en el Medioevo a través de la teoría vertical, y adquirió nueva perspectiva en la época moderna con los aportes de Maquiavelo y Bodin. Finalmente, el estado de excepción tuvo un desarrollo y se le dio un marco jurídico-constitucional en la época contemporánea. Sobre el desarrollo del concepto de "estado de excepción" en las diversas épocas, ver León Zaa (2014, pp. 7-122). Asimismo, sobre el desarrollo histórico de los estados de excepción y su incorporación en las diversas constituciones, ver Gross y Ni Aloáin (2006, pp. 17-46).

2 A su vez, se han distinguido dos teorías en relación con la construcción de los estados de emergencia. Por un lado, se encuentra la teoría centrada en el Estado, en la cual se considera que el Estado tiene un derecho "prelegal" o un derecho no positivo de derecho natural para actuar por su autopreservación. Por otro lado, quienes apoyan la teoría centrada en la Constitución no están de acuerdo con la existencia de poderes prelegales del Estado, sino que consideran que aquellos poderes derivan de la Constitución (Jakab, 2006, p. 467). 
Ahora bien, con carácter previo a analizar los supuestos enunciados, considero apropiado recordar dos cuestiones específicas. Por un lado, hay que distinguir entre los "eventos o situaciones de emergencia" y los "institutos de emergencia": los primeros son acontecimientos reales o fácticos, eventos que perturban el orden constitucional con carácter de emergencia; en cambio, los institutos de emergencia son creaciones del derecho que importan medidas de prevención, seguridad y remedio para contener, atenuar o subsanar las emergencias (Bidart Campos, 1995, p. 301; Dalla Vía, 2006, p. 405). La importancia del estudio de la cuestión radica en que los institutos de emergencia poseen dos características fundamentales: por un lado, acrecientan ciertas competencias del poder, reforzando algún órgano del poder; por el otro, originan una restricción a las libertades, derechos y garantías individuales (Bidart Campos, 1995, p. 301; Gross y Ni Aloaín, 2006, pp. 58-59; Jakab, 2006, pp. 460-464; Loianno, 2005, p. 609; Padilla, 2002, p. 32).

Así, luego de hacer mención de las prescripciones sobre el tema en dos instrumentos internacionales de derechos humanos, analizaré los diversos institutos de excepción de cada país. Para una mejor comprensión de cada uno de ellos, en primer lugar reseñaré la regulación constitucional de cada uno de los institutos. Seguidamente, expondré las cuestiones en común que surgen del análisis de cada uno de ellos, poniendo énfasis a los límites a la aplicación de los institutos de excepción y los alcances de su control.

\section{La suspensión de derechos en los}

\section{instrumentos internacionales de derechos humanos}

Ciertos tratados de derechos humanos prevén, bajo el nombre de "suspensión”, restricciones y limitaciones que pueden recaer en los derechos que ellos reconocen. Cabe precisar, entonces, que para que aquella suspensión sea legítima debe configurarse una genuina situación de emergencia. En este contexto, se ha indicado que aquella suspensión no puede ser causada por cualquier motivo, sino que se configura "con carácter excepcional y por real causa de emergencia” (Bidart Campos, 2000, p. 359). En el mismo sentido, se ha dicho que a fin de que pueda considerarse que hay una emergencia que justifica la suspensión de derechos, debe existir en el país una situación de extrema gravedad y de tal naturaleza que exista una amenaza real (Dulitzky, 2004, p. 111).

Sobre el tema, me detendré especialmente en el artículo 27 de la Conven- 
ción Americana sobre Derechos Humanos y en el artículo 4 del Pacto Internacional de Derechos Civiles y Políticos, referidos al tema bajo análisis.

\subsection{Convención Americana sobre Derechos Humanos}

La Convención Americana sobre Derechos Humanos, en su artículo 27.1., dispone que:

En caso de guerra, de peligro público o de otra emergencia que amenace la independencia o seguridad del Estado parte, éste podrá adoptar disposiciones que, en la medida y por el tiempo estrictamente limitados a las exigencias de la situación, suspendan las obligaciones contraídas en virtud de esta Convención, siempre que tales disposiciones no sean incompatibles con las demás obligaciones que les impone el derecho internacional y no entrañen discriminación alguna fundada en motivos de raza, color, sexo, idioma, religión u origen social.

Así, cabe advertir que el Pacto de San José de Costa Rica admite la suspensión de ciertos derechos reconocidos únicamente en caso: (a) de guerra; (b) de peligro público; o (c) de otra emergencia que amenace la independencia o seguridad del Estado parte. A su vez, en relación con las disposiciones que se adopten para combatir aquellas circunstancias excepcionales, el artículo determina que deben ser "en la medida y por el tiempo estrictamente limitados a las exigencias de la situación”. Esta previsión no solo reafirma la excepcionalidad de las disposiciones que se adopten, sino que exige que su alcance y vigencia temporal se limite a hacer frente a la situación excepcional. Más adelante se realizarán precisiones respecto a las circunstancias que habilitan el mecanismo de la suspensión de garantías.

Seguidamente, en el segundo apartado del citado artículo 27, se establece que la disposición mencionada no autoriza la suspensión de los derechos determinados en los siguientes artículos: 3 (derecho al reconocimiento de la personalidad jurídica), 4 (derecho a la vivienda), 5 (derecho a la integridad personal), 6 (prohibición de la esclavitud y servidumbre), 9 (principio de legalidad y de retroactividad), 12 (libertad de conciencia y de religión), 17 (protección a la familia), 18 (derecho al nombre), 19 (derechos del niño), 20 (derecho a la nacionalidad) y 23 (derechos políticos) ni de las garantías judiciales indispensables para la protección de tales derechos. Sobre el punto, Gelli (2008, p. 407) pone de relieve que pese a la ambigüedad del artículo 27 de la Convención Americana de Derechos Humanos, en especial la denominación del Capítulo IV que 
se refiere a la suspensión de garantías, lo que se suspende durante los estados de excepción son algunos derechos allí consagrados y no las garantías procesales, en tanto que los requisitos de eficacia de estas, establecidos en el artículo 8 de la Convención citada, solo pueden restringirse en la medida extrema de su requerimiento para hacer frente a la emergencia y, todo ello, con suficiente control judicial sustantivo y adjetivo.

Finalmente, se establece también la obligación de informar la situación y su cese a los demás Estados partes. Así, el apartado 3 del artículo 27 determina:

Todo Estado Parte que haga uso del derecho de suspensión deberá informar inmediatamente a los demás Estados Partes en la presente Convención, por conducto del Secretario General de la Organización de los Estados Americanos, de las disposiciones cuya aplicación haya suspendido de los motivos que hayan suscitado la suspensión y de la fecha en que haya dado por terminada tal suspensión.

De este modo, cabe destacar que los Estados partes se encuentran obligados a fundamentar y explicar las razones por las que se hayan dictado normas tendientes a suspender los derechos. Al respecto, se ha indicado que el artículo 27 no exige una declaración explícita de la emergencia para suspender los derechos, aunque en su apartado 3 específica que el Estado que haga uso del "derecho de suspensión" tendrá que informar debidamente a los demás Estados partes de la Convención (Sagüés, 2003, p. 116).

Puede decirse que las exigencias de fondo requeridas por el artículo 27 son, en conjunto, muy similares a las del artículo 15 del Convenio Europeo de Derechos Humanos: las circunstancias deben ser actuales, excepcionales y de una gravedad tal que se afecte al Estado o a su población de forma importante. Además de estos requisitos, las cláusulas van acompañadas de una serie de garantías procesales que refuerzan los obstáculos contra posibles abusos (Úbeda de Torres, 2007, p. 587). ${ }^{3}$

La Corte Interamericana de Derecho Humanos se ha expedido en dos opiniones consultivas sobre el artículo 27: en la Opinión Consultiva 8 del 30/1/1987 y en la Opinión Consultiva 9 del 6/10/1987. En la primera de ellas, por unanimidad, la Corte resolvió que

3 Sobre la comparación de ambos textos, ver también Gros Espiell (1991, pp. 121-132). 
en que los procedimientos jurídicos consagrados en los artículos $25.1 .^{4}$ y 7.6..$^{5}$ de la Convención Americana sobre Derechos Humanos no pueden ser suspendidos conforme al artículo 27.2. de la misma, porque constituyen garantías judiciales indispensables para proteger derechos y libertades que tampoco pueden suspenderse según la misma disposición.

Por otro lado, en la Opinión Consultiva 9/1987, el tribunal interamericano se expidió en relación con el requerimiento del Gobierno de la República Oriental del Uruguay, que había sometido al citado tribunal una solicitud de opinión consultiva sobre el alcance de la prohibición de suspender las garantías judiciales indispensables para la protección de los derechos mencionados en el artículo 27.2. de la Convención Americana. La Corte Interamericana arribó a tres conclusiones. Por unanimidad, resolvió que

deben considerarse como garantías judiciales indispensables no susceptibles de suspensión, según lo establecido en el artículo 27.2 de la Convención, el hábeas corpus (art. 7.6), el amparo, o cualquier otro recurso efectivo ante los jueces o tribunales competentes (art. 25.1), destinado a garantizar el respeto a los derechos y libertades cuya suspensión no está autorizada por la misma Convención.

\section{En segundo lugar, dispuso también que}

deben considerarse como garantías judiciales indispensables que no pueden suspenderse, aquellos procedimientos judiciales, inherentes a la forma democrática representativa de gobierno (art. 29.c), previstos en el derecho interno de los Estados Partes como idóneos para garantizar la plenitud del ejercicio de los derechos a que se refiere el artículo 27.2 de la Convención y cuya supresión o limitación comporte la indefensión de tales derechos.

En tercer lugar, indicó que las mencionadas garantías judiciales "deben ejercitarse dentro del marco y según los principios del debido proceso legal, recogidos por el art. 8 de la Convención”.

$4 \quad$ El artículo 25, "Protección Judicial”, en su apartado 1 establece que: "Toda persona tiene derecho a un recurso sencillo y rápido o a cualquier otro recurso efectivo ante los jueces o tribunales competentes, que la ampare contra actos violen sus derechos fundamentales reconocidos por la Constitución, la ley o la presente Convención, aun cuando tal violación sea cometida por personas que actúen en ejercicio de sus funciones oficiales".

5 El artículo 7, "Derecho a la Libertad Personal", en su apartado 6 determina que: "Toda persona privada de su libertad tiene derecho a recurrir ante un juez o tribunal competente, a fin de que éste decida, sin demora, sobre la legalidad de tal amenaza dicho recurso no puede ser restringido ni abolido. Los recursos podrán interponerse por sí o por otra persona”. 


\title{
3.2. Pacto Internacional de Derechos Civiles y Políticos
}

El artículo 4.1. del Pacto Internacional de Derechos Civiles y Políticos señala que:

\begin{abstract}
En situaciones excepcionales que pongan en peligro la vida de la nación y cuya existencia haya sido proclamada oficialmente, los Estados Partes en el presente Pacto podrán adoptar disposiciones que, en la medida estrictamente limitada a las exigencias de la situación, suspendan las obligaciones contraídas en virtud de este Pacto, siempre que tales disposiciones no sean incompatibles con las demás obligaciones que les impone el derecho internacional y no entrañen discriminación alguna fundada únicamente en motivos de raza, color, sexo, idioma, religión u origen social.
\end{abstract}

Las disposiciones de este tratado son más amplias que las de la Convención Americana de Derechos Humanos. Así, se refiere de un modo general a las "situaciones excepcionales que pongan en peligro la vida de la nación". Es interesante destacar que para que el Estado parte pueda suspender las disposiciones del Pacto, la norma pone de relieve de modo especial la necesidad de la declaración de la situación excepcional. A su vez, en el texto citado se establece que las disposiciones que el Estado parte adopte deben estar vinculadas estrechamente a la situación excepcional que se persigue combatir.

En el segundo apartado del citado artículo 4 se establece que la disposición precedente no autoriza suspensión alguna de los artículos 6 (derecho a la vida), 7 (prohibición de torturas y tratos crueles), 8 párrafos 1 y 2 (prohibición de esclavitud y servidumbre), 11 (prohibición de encarcelamiento por no poder cumplir con obligación contractual), 15 (prohibición retroactividad en materia penal), 16 (derecho a la personalidad jurídica) y 18 (libertad de pensamiento, conciencia y religión). Finalmente, en el apartado 3 del citado artículo se establece una disposición análoga a la del artículo 27.3. de la Convención Americana sobre Derechos Humanos.

El Convenio Europeo de Derechos Humanos también prevé como causal para declarar el estado de emergencia la existencia de un peligro para "la vida de la Nación”. En efecto, el artículo 15.1. del Convenio Europeo regula la "derogación" de las obligaciones previstas en el Convenio en caso de estado de excepción, el establece que:

En caso de guerra o de otro peligro público que amenace la vida de la nación, cualquier Alta Parte Contratante podrá tomar medidas que deroguen las obligaciones previstas en el presente Convenio en la estricta medida en que lo exija la situación, y a condición de que tales medidas no estén en contradicción con las restantes obligaciones que dimanan del derecho internacional. 
Así, se ha dicho que tanto el Convenio Europeo de Derecho Humanos como el Pacto de Derechos Civiles y Políticos establecen dos condiciones acumulativas que caracterizan el estado de emergencia y que permiten calificar una situación como tal: que la situación existente sea excepcional y que amenace la vida de la nación (Úbeda de Torres, 2007, p. 583). ${ }^{6}$

\section{Constitucionales americanas}

\subsection{Argentina}

Entre los institutos de emergencia, la Constitución argentina, hasta la reforma de 1994, en su artículo 23, siempre reguló el estado de sitio, aplicable a las emergencias de la guerra (ataque exterior) y a la conmoción interior. En efecto, el mencionado artículo dispone lo siguiente:

En caso de conmoción interior o de ataque exterior que pongan en peligro el ejercicio de esta Constitución y de las autoridades creadas por ella, se declarará en estado de sitio la provincia o territorio en donde exista la perturbación del orden, quedando suspensas allí las garantías constitucionales. Pero durante esta suspensión no podrá el presidente de la República condenar por sí ni aplicar penas. Su poder se limitará en tal caso respecto de las personas, a arrestarlas o trasladarlas de un punto a otro de la Nación, si ellas no prefiriesen salir fuera del territorio argentino.

De forma concordante, el artículo 99, inciso 16 determina que el presidente

[d]eclara en estado de sitio uno o varios puntos de la Nación, en caso de ataque exterior y por un término limitado, con acuerdo del Senado. En caso de conmoción interior sólo tiene esta facultad cuando el Congreso está en receso, porque es atribución que corresponde a este cuerpo. El Presidente la ejerce con las limitaciones prescriptas en el Artículo 23.

A su vez, el artículo 61 establece que "[c]orresponde también al Senado autorizar al presidente de la Nación para que declare en estado de sitio, uno o varios puntos de la República en caso de ataque exterior”. Finalmente, el artículo 75,

6 Sobre la cuestión, se recomienda ver el Informe de la Relatora Especial sobre estados de excepción, Naciones Unidas, E/CN.4/Sub.2/1982/15; los "Principios de Siracusa sobre las Disposiciones de Limitación y Derogación del Pacto Internacional de Derechos Civiles y Políticos" aprobados en Siracusa en 1984, sobre las "situaciones excepcionales que pongan en peligro la vida de la Nación"; y la Observación general 29 del 31/8/2001 del Comité de Derechos Humanos. 
inciso 29 indica que corresponde al Congreso "[d]eclarar en estado de sitio uno o varios puntos de la Nación en caso de conmoción interior, y aprobar o suspender el estado de sitio declarado, durante su receso, por el Poder Ejecutivo".

A su vez, otros autores sostienen que puede incluirse dentro de los institutos de emergencia a la intervención federal, prevista en el artículo 6 de la Constitución, que procede para garantizar la forma republicana de gobierno o repeler invasiones exteriores, y a requisición de sus autoridades constituidas para sostenerlas o restablecerlas si hubiesen sido depuestas por la sedición o por invasión de otra provincia (Dalla Vía 2002, pp. 40-41; Gelli, 2008, p. 390). En lo que respecta al órgano competente para establecer la intervención federal, el artículo 6 de la Constitución alude al "gobierno federal" sin individualizar cuál es el órgano competente. Sin embargo, esta situación es aclarada en los artículos 75 y 99 de la norma fundamental, que regulan las competencias del Congreso y del Poder Ejecutivo, respectivamente. De esta manera, el artículo 75, inciso 31 establece que le corresponde al Congreso "[d]isponer la intervención federal a una provincia o a la ciudad de Buenos Aires". Paralelamente, el artículo 99, inciso 20 determina que el Poder Ejecutivo "[d]ecreta la intervención federal a una provincia o a la ciudad de Buenos Aires en caso de receso del Congreso, y debe convocarlo simultáneamente para su tratamiento”. Finalmente, el segundo párrafo del artículo 75, inciso 31 antes mencionado indica que le corresponde al Congreso "[a]probar o revocar la intervención decretada, durante su receso, por el Poder Ejecutivo”. De lo expuesto, se colige que el titular de la competencia de disponer la intervención federal en el territorio de una provincia es el Congreso y que se otorga aquella competencia limitadamente al órgano ejecutivo, quien, en caso de decretar la intervención federal, debe convocar simultáneamente al Congreso.

Luego de la reforma de 1994, se admitieron dos tipos más de emergencias: las que dan lugar a la delegación legislativa y las que autorizan el dictado de decretos de necesidad y urgencia. La delegación legislativa, según el artículo 76, se admite "en materias determinadas de administración o de emergencia pública, con plazo fijado para su ejercicio y dentro de las bases de la delegación que el Congreso establezca". ${ }^{7}$ A su turno, el artículo 99, inciso 3 prevé que el Poder Ejecutivo

cuando circunstancias excepcionales hicieran imposible seguir los trámites ordinarios previstos por esta Constitución para la sanción de las leyes, y no se trate

7 Al respecto, ver Bianchi (1990), Castro Videla y Maqueda (2017) y Santiago (h) y Thury Cornejo (2003). 
de normas que regulen materia penal, tributaria, electoral o de régimen de los partidos políticos, podrá dictar decretos por razones de necesidad y urgencia. ${ }^{8}$

El último párrafo de la mencionada norma regula el control que le corresponde ejercer al Poder Legislativo sobre los mencionados decretos:

[e]l jefe de gabinete de ministros personalmente y dentro de los diez días someterá la medida a consideración de la Comisión Bicameral Permanente, cuya composición deberá respetar la proporción de las representaciones políticas de cada Cámara. Esta comisión elevará su despacho en un plazo de diez días al plenario de cada Cámara para su expreso tratamiento, el que de inmediato considerarán las Cámaras. Una ley especial sancionada con la mayoría absoluta de la totalidad de los miembros de cada Cámara regulará el trámite y los alcances de la intervención del Congreso.

Complementariamente, el artículo 100, inciso 13 establece que le corresponde al jefe de Gabinete de Ministros "refrendar conjuntamente con los demás ministros los decretos de necesidad y urgencia y los decretos que promulgan parcialmente leyes. Someterá personalmente y dentro de los diez días de su sanción estos decretos a consideración de la Comisión Bicameral Permanente". El trámite y el alcance de la intervención del Congreso no fueron regulados sino hasta el año 2006, fecha en la que se dictó la Ley 26122. En lo que respecta al contralor que le corresponde al Congreso de la Nación, la mencionada norma estableció en su artículo 24 que un decreto solo quedará derogado si ambas Cámaras del Congreso lo rechazan. La doctrina ha criticado lo establecido en la norma (Elias, 2010; Sabsay, 2010), criterio que comparto, pues requerir el rechazo de ambas Cámaras de un decreto de necesidad y urgencia constituye un contrasentido, en tanto para la aprobación de una ley por parte del Congreso se requiere la conformidad de las dos Cámaras, en función de lo estipulado por el artículo 78 de la Constitución nacional. ${ }^{9}$

Por otro lado, cabe precisar que, a raíz de la crisis generada por el Covid-19, la doctrina ha debatido respecto a si correspondía o no declarar el estado de sitio, o bien si el Presidente debía limitarse a dictar decretos de necesidad y

8 Sobre el particular, ver Midón (2012). A su vez, Sacristán (2014) ha estudiado distintos institutos que integran las "medidas de emergencia", como el estado de asamblea, la ley marcial, las facultades extraordinarias o la suma del poder público, el estado de prevención y de alarma, el estado de guerra interno y la revolución.

9 He desarrollado en profundidad las facultades legislativas del presidente en Ylarri (2019a, pp. 147212). 
urgencia. Como lo expuse en otra oportunidad, estimo que ha sido acertado acudir al dictado de estos decretos con fuerza de ley, sin perjuicio del control del adecuado control judicial sobre estos (Ylarri, 2020).

En cuanto a la utilización de los institutos de excepción en la práctica, en Argentina, como en muchos países, se han producido grandes abusos. Así, por ejemplo, en lo que respecta al estado de sitio, se ha indicado que la historia argentina demuestra el abuso que se hizo del instituto y la desviación de poder de los sucesivos gobiernos de iure y de facto, que convirtieron "a la excepción en normalidad y a la transitoriedad en permanencia" (Ekmekdjian, 2008, pp. 284285). En el mismo sentido, se ha dicho que en nuestro país se usó y abusó del estado de sitio y se extendieron hasta límites intolerables las restricciones de los derechos y garantías, a la vez que se fortaleció la rama ejecutiva del poder y se debilitó el principio de separación de poderes. De este modo, la larga vigencia del estado de sitio en la Argentina convirtió un remedio excepcional en un recurso reiterado (Gelli, 2008, pp. 393-395). También, cabe destacar la opinión de Nino (2005), quien sostiene que la institución del estado de sitio "ha sido lisa y llanamente el cementerio de nuestras libertades" (pp. 489-492) y que ha habido abusos al estado de sitio con la correspondiente condescendencia judicial. Del mismo modo, Gargarella (1996, pp. 246-247) sostiene que la Corte Suprema ha actuado con ligereza en temas como la intervención federal o el estado de sitio. Sobre el punto, el autor aduce que en la aplicación de aquellos institutos, el Ejecutivo suele extender su poder hasta puntos extremos, llegando a violentar directamente contra los derechos individuales. Así, afirma que en los momentos de mayor violencia política es cuando cabe esperar una actuación también decidida y enérgica por parte de la Corte Suprema, pero aquella ha asumido una actuación inversa a la que le correspondía.

Lo propio ha ocurrido, por ejemplo, con las normas de emergencia económica. La doctrina es coincidente en la existencia de una emergencia económica permanente en la Argentina desde hace casi un siglo (Bianchi, 1991; Lorenzetti, 2003; Vanossi, 2003; Ylarri, 2019a). Así, cabe destacar que, en un primer momento y a partir del precedente Ercolano ${ }^{10}$-en el cual la Corte Suprema reconoció el poder de policía amplio-, las limitaciones a los derechos individuales con ocasión de la existencia de una emergencia económica se realizaron por medio de una ley formal. Sin embargo, a partir del reconocimiento de la Corte Suprema de la validez de los decretos de necesidad y urgencia en el precedente

10 Corte Suprema de Justicia de la Nación, Ercolano, Agustín c/Lantieri de Renshaw, Julieta s/consignación, 28/4/1922, Fallos: 136:161. 
Peralta ${ }^{11}$ las medidas de emergencia no solo fueron adoptadas por ley formal, sino también a través de los decretos de necesidad y urgencia y por medio de la delegación legislativa. De esta manera, en la Argentina, las crisis económicas y sociales han generado mayores demandas al Estado, y es el Poder Ejecutivo quien ha adquirido un rol preponderante en la adopción de las medidas tendientes a hacer frente a la emergencia económica (Ylarri, 2016). El plazo limitado por el cual deben regir los institutos de excepción ha sido claramente burlado. Pensemos en la Ley $25561^{12}$-dictada en los primeros días del año 2002-, que declaró la emergencia pública sobre numerosas materias y estuvo vigente hasta 2017; incluso, la emergencia social allí declarada rigió hasta el año 2019, inclusive. A fines de aquel año, se dictó la Ley 27541, llamada "de solidaridad social y reactivación productiva”, que nuevamente declaró la emergencia pública en distintas materias y delegó numerosas facultades al Ejecutivo.

\subsection{Bolivia}

La Constitución de Bolivia prevé un capítulo específico con relación a los estados de excepción. En su artículo 137 indica que el presidente del Estado tiene la potestad de declarar el estado de excepción "en caso de peligro para la seguridad del Estado, amenaza externa, conmoción interna o desastre natural”. Según lo estipulado por el artículo 138.I, la vigencia de la declaración del estado de excepción dependerá de la aprobación posterior de la Asamblea Legislativa Plurinacional. Aquella aprobación de la declaración debe indicar "las facultades conferidas y guardará estricta relación y proporción con el caso de necesidad atendida por el estado de excepción”.

Una vez finalizado el estado de excepción, según lo estipula el artículo 139.I, el Ejecutivo debe rendir cuentas a la Asamblea Legislativa Plurinacional "de los motivos que dieron lugar a la declaración del estado de excepción, así como del uso que haya hecho de las facultades conferidas por la Constitución y la ley”.

\subsection{Brasil}

La Constitución de Brasil de 1988 establece en su título V un apartado respecto

11 Corte Suprema de Justicia de la Nación, Peralta, Luis A. y otro c/Estado Nacional (Ministerio de Economía-B.C.R.A), 27/12/1990, Fallos: 313:1513.

12 La Ley 25561 fue prorrogada por las leyes 25972, 26077, 26204, 26339, 26456, 26563, 26729, 26896, 27200 y 27345. 
a la "defensa del estado y las instituciones democráticas", que regula los institutos del estado de defensa y del estado de sitio.

En su artículo 136, en relación con el estado de defensa, indica que el presidente de la República puede, oídos el Consejo de la República y el Congreso de Defensa Nacional, decretar el estado de defensa para preservar o restablecer en breve tiempo, en lugares concretos y determinados "el orden público o la paz social amenazadas por una grave y eminente inestabilidad institucional o afectadas por calamidades naturales de grandes proporciones". A su vez, en el apartado 5, se indica que si el Congreso nacional estuviese en período de vacaciones, será convocado, extraordinariamente, en el plazo de cinco días. Conforme al apartado 6, el Congreso debe examinar el decreto en el plazo de diez días contados desde su recepción, debiendo continuar funcionando en tanto el estado de defensa estuviese en vigor. Finalmente, en el apartado 7 se estipula que si se rechaza el decreto, cesa inmediatamente el estado de defensa.

En lo que respecta al estado de sitio, el artículo 137 de la Constitución brasileña establece que el presidente de la República puede, oídos el Congreso de la República y el Consejo de Defensa Nacional, solicitar al Congreso Nacional autorización para decretar el estado de sitio en los casos de "1. Conmoción grave de repercusión nacional o sucesión de hechos que demuestren la ineficacia de la medida tomada durante el estado de defensa; 2. Declaración de estado de guerra o respuesta a una agresión armada extranjera”. El mismo artículo determina que al solicitar autorización para decretar el estado de sitio o su prórroga, el presidente de la República "señalará los motivos determinantes de la solicitud".

Por su parte, el artículo 138.1 indica que el decreto de estado de sitio debe indicar su duración, las normas necesarias para su ejecución y las garantías constitucionales que quedan suspendidas. En el caso del primer supuesto del artículo 137, es decir, en caso de conmoción grave de repercusión nacional, el estado de sitio no puede decretarse "por más de treinta días ni prorrogarse, de cada vez, por plazo superior”. En el caso del segundo supuesto del mencionado artículo, esto es, en caso de declaración de estado de guerra o respuesta a una agresión armada extranjera, el estado de sitio puede ser decretado por todo el tiempo que perdure la guerra o la agresión armada extranjera.

A su vez, según determina el artículo 138.2, si el presidente solicita la autorización para decretar el estado de sitio durante período de vacaciones parlamentarias, el presidente del Senado Federal, de inmediato, debe convocar extraordinariamente al Congreso Nacional para que este se reúna dentro de 
cinco días a fin de examinar el acto. Finalmente, el artículo 138.3 indica que el Congreso Nacional permanece en funcionamiento hasta el término de las medidas coercitivas.

Por otro lado, cabe destacar que el artículo 62 de la Constitución brasileña establece el supuesto de "medidas provisionales" que puede adoptar el presidente.

En caso de relevancia y urgencia, el Presidente de la República podrá adoptar medidas provisionales, con fuerza de ley, debiendo someterlas de inmediato al congreso Nacional, el cual estando en vacaciones será convocado extraordinariamente para reunirse en el plazo de cinco días.

A su vez, se establece que "las medidas provisionales perderán eficacia desde la adopción si no fueran convertidas en ley en el plazo de treinta días, a partir de su publicación, debiendo el Congreso Nacional regular las relaciones derivadas de ellas". ${ }^{13}$

\subsection{Chile}

La Constitución de Chile de 1980, con sus posteriores reformas, establece un apartado especial respecto a los "estados de excepción constitucional", el cual incluye el estado de asamblea, el estado de sitio, el estado de catástrofe y el estado de emergencia.

De modo general, el artículo 39 determina que el ejercicio de los derechos y garantías que la Constitución asegura a todas las personas solo puede ser afectado bajo las siguientes situaciones de excepción: "Guerra externa o interna, conmoción interior, emergencia y calamidad pública, cuando afecten gravemente el normal desenvolvimiento de las instituciones del Estado".

El artículo 40 de la Constitución chilena regula el estado de asamblea y el estado de sitio. El estado de asamblea se declara "en caso de guerra exterior" y el estado de sitio "en caso de guerra interna o grave conmoción interior". Ambos institutos son declarados "por el Presidente de la República, con acuerdo del Congreso Nacional”. En cuanto a su duración, el último párrafo del citado artículo indica que

13 Sobre las medidas provisionales se ha dado un fenómeno de reiteración en la utilización de este mecanismo en Brasil, pero la Corte ha renunciado a poner un freno a esas reiteraciones (Castro E. Camargo, 2011). 
[1]a declaración de estado de sitio sólo podrá hacerse por un plazo de quince días, sin perjuicio de que el Presidente de la República solicite su prórroga. El estado de asamblea mantendrá su vigencia por el tiempo que se extienda la situación de guerra exterior, salvo que el Presidente de la República disponga su suspensión con anterioridad.

En lo que respecta al estado de catástrofe, el artículo 41 de la Constitución chilena indica que lo declara el presidente "en caso de calamidad pública". A su vez, en el segundo párrafo se indica que el presidente de la República está obligado a informar al Congreso Nacional de las medidas adoptadas en virtud del estado de catástrofe. A continuación, se establece que "el Congreso Nacional único podrá dejar sin efecto la declaración transcurridos ciento ochenta días desde ésta si las razones que la motivaron hubieran cesado en forma absoluta".

El artículo 42 señala que el estado de emergencia se configura "en caso de grave alteración del orden público o de grave daño para la seguridad de la Nación”, y que le corresponde al presidente de la República su declaración, debiendo determinar las zonas afectadas por dichas circunstancias. Respecto al plazo, resalta que "no podrá extenderse por más de quince días, sin perjuicio de que el Presidente de la República pueda prorrogarlo por igual período. Sin embargo, para sucesivas prórrogas, el Presidente requerirá siempre del acuerdo del Congreso Nacional".

Cabe recordar que el presidente Piñera declaró el estado de emergencia como consecuencia de las manifestaciones que comenzaron en el mes de octubre de 2019.

El artículo 44 señala que una ley orgánica constitucional regulará los estados de excepción, así como su declaración y la aplicación de las medidas legales y administrativas que procediera adoptar bajo aquellos, y que las medidas que se adopten durante los estados de excepción no podrán, bajo ninguna circunstancia, prolongarse más allá de la vigencia de estos.

Por último, cabe señalar que la Constitución chilena veda al Poder Judicial controlar la situación de emergencia invocada por la autoridad pública para dictar los estados de excepción. En efecto, el artículo 45 determina que "los tribunales de justicia no podrán calificar los fundamentos ni las circunstancias de hecho invocados por la autoridad para decretar los estados de excepción, sin perjuicio de lo dispuesto en el artículo 39”. 


\subsection{Colombia}

Los "estados de excepción" en Colombia están regulados en el Capítulo VI de la Constitución de 1991. Se prevé el estado de guerra exterior, el estado de conmoción interior y el estado de emergencia.

El estado de guerra exterior se encuentra regulado en el artículo 212, el cual establece que puede ser declarado por el presidente de la República con la firma de todos los ministros, y mediante su declaración "el Gobierno tendrá las facultades estrictamente necesarias para repeler la agresión, defender la soberanía, atender los requerimientos de la guerra, y procurar el restablecimiento de la normalidad".

El estado de conmoción interior puede ser declarado, según el artículo 213 de la Constitución

[e]n caso de grave perturbación del orden público que atente de manera inminente contra la estabilidad institucional, la seguridad del Estado, o la convivencia ciudadana, y que no pueda ser conjurada mediante el uso de las atribuciones ordinarias de las autoridades de Policía.

Este instituto de excepción es declarado por el presidente de la República con la firma de todos los ministros "por término no mayor de noventa días, prorrogable hasta por dos períodos iguales, el segundo de los cuales requiere concepto previo y favorable del Senado de la República".

En relación con los dos institutos mencionados, el artículo 214 indica "[1]os decretos legislativos llevarán la firma del Presidente de la República y todos sus ministros y solamente podrán referirse a materias que tengan relación directa y específica con la situación que hubiere determinado la declaratoria del Estado de Excepción”.

Finalmente, en relación con el estado de emergencia, el artículo 215 establece que puede ser declarado cuando sobrevengan hechos distintos de los previstos en los artículos 212 y 213 antes mencionados y que "perturben o amenacen perturbar en forma grave e inminente el orden económico, social y ecológico del país, o que constituyan grave calamidad pública”. Asimismo, se prevé que es el presidente, junto con la firma de todos los ministros, quien debe declarar el estado de emergencia. En cuanto al plazo, puede ser por períodos de hasta treinta días, pero que en total no excedan los noventa.

Esta situación excepcional permite al presidente dictar decretos con fuerza de ley, debiéndose expresar allí los motivos de la declaración: "Mediante tal declaración, que deberá ser motivada, podrá el Presidente, con la firma de todos 
los ministros, dictar decretos con fuerza de ley, destinados exclusivamente a conjurar la crisis y a impedir la extensión de sus efectos".

A su vez, se establece la responsabilidad del presidente y de los ministros "cuando declaren el Estado de Emergencia sin haberse presentado alguna de las circunstancias previstas en el inciso primero". Cabe destacar también que en el texto constitucional se prevé específicamente la intervención de la Corte Constitucional:

El Gobierno enviará a la Corte Constitucional al día siguiente de su expedición los decretos legislativos que dicte en uso de las facultades a que se refiere este artículo, para que aquella decida sobre su constitucionalidad. Si el Gobierno no cumpliere con el deber de enviarlos, la Corte Constitucional aprehenderá de oficio y en forma inmediata su conocimiento. ${ }^{14}$

Por otro lado, en relación con la situación que da lugar al dictado de estos institutos de excepción, la Corte Constitucional colombiana ha indicado que el principio de temporalidad apunta a que toda medida de excepción tenga una duración limitada de acuerdo con las exigencias de la situación. Es decir que se prohíbe la permanencia de las medidas de excepción una vez finalizada la emergencia, así como la adopción de medidas por tiempo ilimitado. De lo contrario, se daría el fenómeno de la institucionalización de los regímenes de excepción. ${ }^{15}$

Por último, aquel tribunal sostuvo que la regulación constitucional de los estados de excepción busca limitar la discrecionalidad del Gobierno en su declaración y ejercicio.

La Carta Politica de 1886 -con sus reformas- no estableció controles suficientes para prevenir su abuso. Su declaratoria, por ejemplo, era considerada un acto meramente político y no susceptible de control jurídico, esto es, una potestad completamente discrecional del Presidente de la República. Así, frente a los abusos cometidos bajo la figura del estado de sitio durante la vigencia de la Constitución Política de 1886, que de exceptivo pasó a ser crónico, y en precaución ante la acumulación extraordinaria de poderes en manos del ejecutivo, la Carta Política de 1991 estable-

14 En relación con la emergencia económica en Colombia y su utilización en el contexto del presidencialismo colombiano, ver Ortiz Gutiérrez (2017).

15 Sentencia C-219/11, del 30 de marzo de 2011, sobre la Revisión oficiosa del Decreto Legislativo 015 de 2011 "Por el cual se establecen los límites máximos de velocidad para garantizar la seguridad vial en el Estado de Emergencia Económica, Social y Ecológica" (expediente RE-194). Ver también la Sentencia C-216/11, del 29 de marzo de 2011, por el cual se revisó la constitucionalidad del Decreto 020 del 7 de enero de 2011 "Por el cual se declara el Estado de Emergencia Económica, Social y Ecológica por razón de grave calamidad pública” (expediente RE-19). 
ció un estricto régimen regulatorio de los estados de excepción para mantener la plena vigencia del Estado de Derecho, aún en periodos de anormalidad, en guarda del principio democrático, de la separación de poderes y de la primacía de los derechos fundamentales. La alteración extraordinaria de la normalidad admite, en el constitucionalismo, la posibilidad de la alteración excepcional de las competencias legislativas. Si mediante leyes de facultades extraordinarias el Congreso de la República puede habilitar al Presidente de la República para el ejercicio de precisas funciones legislativas, a través de los estados de excepción, el propio Jefe de Gobierno se reviste a sí mismo de poderes de legislación, sin la mediación de otro poder. De ahí la necesidad de que el control de constitucionalidad de la declaración de estados de excepción y el ejercicio de los poderes que de allí emanan, sea jurisdiccional, automático, integral y estricto, sin perjuicio del control político constitucionalmente previsto. Al otorgar poderes excepcionales dirigidos a conjurar la crisis extraordinaria, se faculta al Ejecutivo para fijar contenciones al régimen jurídico ordinario y establecer restricciones a los derechos de los ciudadanos, cuidando en todo caso de no introducir alteraciones desproporcionadas al orden legal vigente y de minimizar las limitaciones de los derechos durante su vigencia. ${ }^{16}$

\section{Asimismo, la Corte Constitucional indicó que}

los estados de excepción no excepcionan la Constitución y no son, ni pueden ser un Estado de facto. Si bien la Carta Política le confiere al Presidente de la República poderes extraordinarios, éstos no revisten un grado absoluto, al encontrarse limitados por diversos tipos de controles que buscan impedir los excesos y a la vez garantizar los principios fundamentales que soportan el Estado de derecho. ${ }^{17}$

\subsection{Ecuador}

La Constitución ecuatoriana de 2008 prevé una sección específica titulada "estados de excepción”, y en su artículo 164 se indica que el estado de excepción podrá ser declarado por el presidente de la República "en caso de agresión, conflicto armado internacional o interno, grave conmoción interna, calamidad pública o desastre natural". Se establece, a su vez, que debe observar los principios de necesidad, proporcionalidad, legalidad, temporalidad, territorialidad y razonabilidad, y que el decreto que establezca el estado de excepción contendrá, entre otras cuestiones, "la determinación de la causal y su motivación".

16 Sentencia C-156/11, del 9 de marzo de 2011, sobre la Revisión de constitucionalidad del Decreto 4580 del 7 de diciembre de 2010, "Por el cual se declara el estado de emergencia económica, social y ecológica por razón de grave calamidad pública” (expediente RE-171).

Ídem. 
Asimismo, el artículo 166 establece la obligación de notificar la declaración del estado de excepción a la Asamblea Nacional, a la Corte Constitucional y a los organismos internacionales que corresponda. A su vez, determina que "[s]i las circunstancias lo justifican, la Asamblea Nacional podrá revocar el decreto en cualquier tiempo, sin perjuicio del pronunciamiento que sobre su constitucionalidad pueda realizar la Corte Constitucional”, distinguiéndose así el control político que se realiza en la Asamblea Nacional del control de constitucionalidad que hace el órgano correspondiente.

En lo que respecta a la vigencia del estado de excepción, se establece que

[e]l decreto de estado de excepción tendrá vigencia hasta un plazo máximo de sesenta días. Si las causas que lo motivaron persisten podrá renovarse hasta por treinta días más, lo cual deberá notificarse. Si el Presidente no renueva el decreto de estado de excepción o no lo notifica, éste se entenderá caducado.

Cuando las causas que motivaron el estado de excepción desaparezcan, la Presidenta o Presidente de la República decretará su terminación y lo notificará inmediatamente con el informe correspondiente.

\subsection{México}

El artículo 29 de la Constitución mexicana dispone que

[e]n los casos de invasión, perturbación grave de la paz pública, o de cualquier otro que ponga a la sociedad en grave peligro o conflicto solamente el Presidente de los Estados Unidos Mexicanos, con la aprobación del Congreso de la Unión o de la Comisión Permanente cuando aquel no estuviere reunido, podrá restringir o suspender en todo el país o en lugar determinado el ejercicio de los derechos y las garantías que fuesen obstáculo para hacer frente, rápida y fácilmente a la situación.

\section{Al mismo tiempo, establece que aquella medida debe ser adoptada}

por un tiempo limitado, por medio de prevenciones generales y sin que la restricción o suspensión se contraiga a determinada persona. Si la restricción o suspensión tuviese lugar hallándose el Congreso reunido, éste concederá las autorizaciones que estime necesarias para que el Ejecutivo haga frente a la situación; pero si se verificase en tiempo de receso, se convocará de inmediato al Congreso para que las acuerde. ${ }^{18}$

18 Este primer párrafo del artículo 29 fue reformado en 2014 (Párrafo reformado DOF 10/2/2014). 
En los siguientes párrafos, el artículo se refiere a los derechos de los que no puede suspenderse su ejercicio; a la necesidad de fundar y motivar las medidas que se adopten y los requisitos exigidos para su validez; ${ }^{19}$ a los efectos de las medidas llevadas a cabo una vez finalizada la restricción o suspensión de los derechos; y al control de la Suprema Corte de Justicia de la Nación sobre la constitucionalidad y validez de las medidas dictadas durante la restricción o suspensión. ${ }^{20}$

\subsection{Paraguay}

La Constitución de Paraguay de 1992, en su título III "del estado de excepción”, específicamente en su artículo 288, establece la forma de la declaración del estado de excepción, sus causales, la vigencia y sus plazos.

Sobre el particular, determina que el Congreso o el Poder Ejecutivo están facultados para declarar el estado de excepción "en caso de conflicto armado internacional, formalmente declarado o no, o de grave conmoción interior que ponga en inminente peligro el imperio de esta Constitución o el funcionamiento regular de los órganos creados por ella”. La declaración del estado de excepción puede ser en todo o en parte del territorio nacional y por un término de sesenta días como máximo. En el caso de que dicha declaración fuera efectuada por el Poder Ejecutivo, la medida debe ser aprobada o rechazada por el Congreso dentro del plazo de cuarenta y ocho horas. Este término de sesenta días puede prorrogarse por períodos de hasta treinta días sucesivos, para lo cual se requiere mayoría absoluta de ambas Cámaras.

A su vez, se indica que durante el receso parlamentario el Poder Ejecutivo puede decretar, por única vez, el estado de excepción por un plazo no mayor de treinta días, pero debe someterlo dentro de los ocho días a la aprobación o rechazo del Congreso, el cual quedará convocado de pleno derecho a sesión extraordinaria únicamente para tal efecto.

Por otro lado, se requiere que el decreto o la ley que declare el estado de excepción contengan "las razones y los hechos que se invoquen para su adop-

19 "La restricción o suspensión del ejercicio de los derechos y garantías debe estar fundada y motivada en los términos establecidos por esta Constitución y ser proporcional al peligro a que se hace frente, observando en todo momento los principios de legalidad, racionalidad, proclamación, publicidad y no discriminación."

20 "Los decretos expedidos por el Ejecutivo durante la restricción o suspensión, serán revisados de oficio e inmediatamente por la Suprema Corte de Justicia de la Nación, la que deberá pronunciarse con la mayor prontitud sobre su constitucionalidad y validez." 
ción, el tiempo de su vigencia y el territorio afectado, así como los derechos que restrinja”. Por su parte, el Congreso, por mayoría absoluta de votos, puede disponer en cualquier momento el levantamiento del estado de excepción "si considerase que cesaron las causas de su declaración”.

\subsection{Perú}

La Constitución peruana de 1993 establece un capítulo específico sobre el tema titulado "régimen de excepción". Se prevé el estado de emergencia y el estado de sitio. De este modo, en su artículo 137 se determina que el presidente de la República, con acuerdo del Consejo de Ministros, puede decretar en todo el territorio nacional, o en parte de él, y dando cuenta al Congreso o a la Comisión Permanente:

1. El estado de emergencia, "en caso de perturbación de la paz o del orden interno, de catástrofe o de graves circunstancias que afecten la vida de la Nación”, previsto en su apartado 1.

2. El estado de sitio, para casos "de invasión, guerra exterior, guerra civil, o peligro inminente de que se produzcan”, regulado en su apartado 2.

\subsection{Uruguay}

En lo que respecta a los institutos de excepción regulados en la Constitución uruguaya, cabe resaltar el artículo 168, el cual establece las atribuciones del presidente de la República. En su inciso 17, se dispone que le corresponde

[t]omar medidas prontas de seguridad en los casos graves e imprevistos de ataque exterior o conmoción interior, dando cuenta, dentro de las veinticuatro horas a la Asamblea General, en reunión de ambas Cámaras o, en su caso, a la Comisión Permanente, de lo ejecutado y sus motivos, estándose a lo que éstas últimas resuelvan.

Cabe citar también las disposiciones del artículo 31 que establecen que

[1]a seguridad individual no podrá suspenderse sino con la anuencia de la Asamblea General, o estando ésta disuelta o en receso, de la Comisión Permanente, y en el caso extraordinario de traición o conspiración contra la patria; y entonces sólo para la aprehensión de los delincuentes, sin perjuicio de lo dispuesto en el inciso 17 del Artículo 168. 
Finamente, en el artículo 253 se prevé la ampliación de la jurisdicción militar en caso de guerra. ${ }^{21}$

\title{
4.11. Venezuela
}

La Constitución venezolana prevé un capítulo específico sobre los "estados de excepción”. De modo general, el artículo 337 indica que el presidente de la República, en Consejo de Ministros, podrá decretar los estados de excepción. Establece que se califican expresamente como tales

\begin{abstract}
las circunstancias de orden social, económico, político, natural o ecológico, que afecten gravemente la seguridad de la Nación, de las instituciones y de los ciudadanos, a cuyo respecto resultan insuficientes las facultades de las cuales se disponen para hacer frente a tales hechos.
\end{abstract}

A continuación, la Constitución venezolana enumera, en su artículo 338, los diversos estados de excepción.

En primer lugar, determina que puede decretarse el estado de alarma "cuando se produzcan catástrofes, calamidades públicas u otros acontecimientos similares que pongan seriamente en peligro la seguridad de la Nación o de sus ciudadanos o ciudadanas". Indica que dicho estado de excepción durará hasta treinta días, siendo prorrogable por treinta días más.

El texto constitucional venezolano, a diferencia de otras constituciones analizadas, también prevé específicamente el "estado de emergencia económica", que puede decretarse "cuando se susciten circunstancias económicas extraordinarias que afecten gravemente la vida económica de la Nación”. Determina que su duración será de sesenta días, prorrogables por un plazo igual.

A su vez, establece que puede decretarse "el estado de conmoción interior o exterior en caso de conflicto interno o externo, que ponga seriamente en peligro la seguridad de la Nación, de sus ciudadanos o de sus instituciones". Este instituto se prolonga hasta por noventa días, siendo prorrogable hasta por noventa días más.

La última parte del artículo 339 determina que la aprobación de la prórroga de los estados de excepción corresponde a la Asamblea Nacional.

Finalmente, resta observar que, según el artículo 339, el decreto que declare el estado de excepción debe ser

21 Sobre los estados de excepción en Uruguay, ver Pérez Pérez (1999, pp. 121 y ss.). 
presentado, dentro de los ocho días siguientes a su promulgación, a la Asamblea Nacional, o a la Comisión Delegada, para su consideración y aprobación, y a la Sala Constitucional del Tribunal Supremo de Justicia, para que se pronuncie sobre su constitucionalidad.

Se indica, a su vez, que el decreto debe cumplir con las exigencias, principios y garantías establecidos en el Pacto Internacional de Derechos Civiles y Políticos y en la Convención Americana sobre Derechos Humanos.

Finalmente, cabe señalar que en caso de que cesen las causas que lo motivaron, la declaración del instituto de excepción debe ser dejada sin efecto. Sobre el punto, el artículo citado indica que el presidente de la República "puede solicitar su prórroga por un plazo igual, y será revocado por el Ejecutivo Nacional o por la Asamblea Nacional o por su Comisión Delegada, antes del término señalado, al cesar las causas que lo motivaron”.

\section{Constitución de Estados Unidos}

La Constitución de Estados Unidos de 1787 no contiene disposiciones específicas respecto a los estados de excepción. Sin perjuicio de ello, cabe destacar que esta norma constitucional establece ciertas previsiones con respecto al caso de guerra. Así, el artículo I en su sección 8 le otorga al Congreso la competencia de declarar la guerra. A su vez, en la sección 9 del mismo artículo se expresa que "el privilegio del habeas corpus no se suspenderá, salvo cuando la seguridad pública lo exija en los casos de rebelión o invasión”. 22

En este contexto, se ha dicho que con la sola excepción de la suspensión del writ of habeas corpus, para hacer frente a situaciones de guerra o de crisis, el texto fundamental norteamericano no ha previsto mecanismo alguno ante supues-

22 Otras disposiciones en relación con la guerra están previstas en el artículo I, sección 10 ("Sin dicho consentimiento del Congreso ningún Estado podrá establecer derechos de tonelaje, mantener tropas o navíos de guerra en tiempo de paz, celebrar convenio o pacto alguno con otro Estado o con una potencia extranjera, o hacer la guerra, a menos de ser invadido realmente o de hallarse en peligro tan inminente que no admita demora"); en el artículo III, sección 3 ("La traición contra los Estados Unidos sólo consistirá en hacer la guerra en su contra o en unirse a sus enemigos, impartiéndoles ayuda y protección. A ninguna persona se le condenará por traición si no es sobre la base de la declaración de los testigos que hayan presenciado el mismo acto perpetrado abiertamente o de una confesión en sesión pública de un tribunal”); en la Enmienda III ("En tiempo de paz a ningún militar se le alojará en casa alguna sin el consentimiento del propietario; ni en tiempo de guerra, como no sea en la forma que prescriba la ley"), y en la Enmienda V ("Nadie estará obligado a responder de un delito castigado con la pena capital o con otra infamante si un gran jurado no lo denuncia o acusa, a excepción de los casos que se presenten en las fuerzas de mar o tierra o en la milicia nacional cuando se encuentre en servicio efectivo en tiempo de guerra o peligro público"). 
tos de necesidad. Sin embargo, se destaca que no han faltado situaciones de emergencia en el derecho norteamericano. Diversos presidentes han adoptado medidas necesarias para hacer frente a las situaciones de crisis, medidas que, en tiempos normales, son de exclusiva competencia del Congreso (Álvarez García, 1996, pp. 114-115). De este modo, se pone como ejemplo los casos de Abraham Lincoln durante la Guerra de Secesión, de Theodor Roosevelt o Woodrow WiIson en la Primera Guerra Mundial, de Franklin D. Roosevelt en la Segunda Guerra Mundial o de Harry Truman en los inicios de la Guerra Fría. ${ }^{23}$

En lo que respecta al caso de Lincoln, el Congreso ratificó con posterioridad diversas medidas llevadas a cabo por el Presidente, aun cuando fueron adoptadas fuera de sus competencias. ${ }^{24} \mathrm{~A}$ efectos de fundamentar el ejercicio de dichas facultades, Lincoln argumentó no solo con base en fundamentos jurídicos, sino también sobre conceptos más amplios -como los políticos, prudenciales o pragmáticos-, señalando que la Constitución debería ser leída en el sentido de que le otorga al presidente todos los poderes de hacer lo necesario para preservar la

23 A su vez, se ha dicho que las actividades de emergencia fueron numerosas en la posguerra debido a que Estados Unidos pasó la mayor parte de las tres décadas siguientes a 1945 ya sea involucrado en un conflicto armado o en una postura de cuasi-guerra requerida por su continua confrontación con la Unión Soviética. Por lo tanto, el ejercicio de los poderes supuestamente temporales se convirtió en una característica permanente del Gobierno de Estados Unidos. Las declaraciones de emergencia nacional emitidas por Roosevelt en 1939 y 1941, aunque inspirada en la Segunda Guerra Mundial, se mantuvieron en vigor hasta 1952. En 1950, después del estallido de la guerra de Corea, el presidente Harry Truman proclamó la existencia de otra emergencia nacional, que se mantuvo en vigor incluso después de la retirada estadounidense de Vietnam en 1973. La persistencia de situaciones de emergencia nacional declaradas por el Presidente mantuvieron operativos cientos de estatutos especiales, cada uno de los cuales requiere una emergencia para ser eficaz, y muchos de ellos delegan amplias facultades discrecionales para el Ejecutivo. De este modo, en 1974, el Comité Especial de Emergencias Nacionales y Poderes de Emergencia Delegados llegó a la conclusión de que el Gobierno de emergencia se había convertido en la norma en los Estados Unidos. Al respecto, ver Belknap (1983, pp. 67 y ss.).

En este sentido, cabe destacar que existe un trabajo muy completo con relación a los poderes de emergencia en Estados Unidos. En efecto, el Comité Especial de Emergencias y Poderes Delegados de Emergencia del Senado de Estados Unidos le encomendó a Harold Relyea que redactara cronológicamente la historia del Gobierno de Estados Unidos durante las emergencias (Relyea, 1974).

24 En este sentido, se ha dicho que entre el 4 de abril y el 4 de julio de 1861 Lincoln demostró seguramente el mayor y más impresionante despliegue del Poder Ejecutivo en la historia de Estados Unidos. Actuando como protector de la Unión, hizo un llamamiento a las milicias, impuso un bloque en los puertos de los Estados del Sur, pagó fondos desproporcionados a personas privadas no autorizadas a recibir esos pagos, autorizó al comandante del Ejército a suspender el writ of habeas corpus en el área entre Filadelfia y Washington -y luego entre el área abarcada entre Washington y Nueva York- y amplió el ejército y la marina más allá de los límites fijados por el Congreso. Para el momento en que el Congreso pudo intervenir, se dice que aquel órgano no tuvo otra opción que ratificar lo actuado por el Presidente a través del recurso a la técnica del bill of indemnity (Gross y Ní Aoláin, 2006, pp. 47-48). 
Nación y la Constitución misma, remarcando que la Constitución no es un pacto suicida (Lincoln, citado en Fallon Jr., 2013, p. 334). ${ }^{25}$ Sin embargo, la Suprema Corte norteamericana se pronunció en el caso Ex parte Lambdin P. Milligan ${ }^{26}$ de 1866 sobre la ilegalidad de las garantías constitucionales relativas a la libertad individual y, en general, de la suspensión de la Constitución en períodos de crisis. Allí, la Suprema Corte dispuso que autorizar a las autoridades militares a juzgar a civiles -en áreas donde los tribunales civiles estaban funcionando- violaba la Enmienda V y la VI. En efecto, se puso de relieve que la Constitución está vigente aun en cualquier período de crisis. ${ }^{27} \mathrm{~A}$ su vez, en el citado precedente se indicó que la ley marcial no podía declararse simplemente ante una amenaza de invasión, sino que la necesidad debía ser real y presente. ${ }^{28}$

Se ha dicho que durante la Primera Guerra Mundial y con posterioridad, la Suprema Corte modificó sustancialmente la interpretación de la Constitución efectuada en el caso Ex parte Lambdin P. Milligan. Así, con relación a las situaciones de emergencia y su contextualización en la Constitución, en el caso Wilson v. New, de 1917, la Suprema Corte norteamericana expresó que

mientras la emergencia no crea poder, puede, en cambio, suministrar la ocasión para el ejercicio del poder; y aunque no puede dar vida a un poder que no ha

25 En este contexto, Fallon Jr. (2003) expresa que a la hora de analizar esta situación de crisis, la Suprema Corte debía realizar un argumento constitucional que resultara persuasivo, bajo las circunstancias, no solo al Congreso, sino también a los ciudadanos americanos. Al respecto, el autor señala que: "In cases of true emergency, such as that which Lincoln confronted at the outset of the Civil War, the ultimate court under the Constitution of the United States may be the court of public opinion. When the President and the courts differ in their interpretations of the Constitution, the American people ordinarily think the President should accept the courts' judgment. In wartime, the situation may sometimes be different. Lincoln's political stature did not suffer much from his defiance of a judicial order in Ex parte Merryman, nor has his historical reputation diminished" (Fallon Jr., 2013, p. 319).

Mucho tiempo después, aquella expresión dio lugar a un libro de Posner (2006), quien analiza las restricciones de derechos en épocas de emergencia.

26 Suprema Corte de los Estados Unidos, Ex parte Lambdin P. Milligan, 71 U.S. 2 (1866).

27 En efecto, la Suprema Corte indicó que: "The Constitution of the United States is a law for rulers and people, equally in war and in peace, and covers with the shield of its protection all classes of men, at all times and under all circumstances. No doctrine involving more pernicious consequences was ever invented by the wit of man than that any of its provisions can be suspended during any of the great exigencies of government. Such a doctrine leads directly to anarchy or despotism, but the theory of necessity on which it is based is false, for the government, within the Constitution, has all the powers granted to it which are necessary to preserve its existence, as has been happily proved by the result of the great effort to throw off its just authority" (pp. 120-121).

28 "Martial law cannot arise from a threatened invasion. The necessity must be actual and present, the invasion real, such as effectually closes the courts and deposes the civil administration." (p. 127) 
existido nunca, sin embargo, puede suministrar una razón para el ejercicio de un poder existente ya gozado. ${ }^{29}$

De este modo, en el precedente Wilson v. New, el Chief Justice White sentó las bases sobre las cuales la Suprema Corte, en las próximas dos décadas, erigiría la doctrina de los poderes de emergencia. En las primeras etapas de la construcción, sin embargo, se ha precisado que los jueces que construyeron esta doctrina no reconocieron explícitamente sus fundamentos (Belknap, 1983, p. 67).

Así, en Highland v. Russell Car EJ Snow Plow Co., de 1929,30 el máximo tribunal norteamericano confirmó tanto las disposiciones de la Lever Act que autorizó al Presidente a fijar los precios del carbón, como los reglamentos promulgados por el presidente Wilson para hacer cumplir esta disposición en un caso en el que se pretendía declarar su inconstitucionalidad por violar la libertad de contratar, garantizada por la Enmienda V. De acuerdo con el Justice Butler, quien escribió para la mayoría, el estatuto y los reglamentos eran ejercicios adecuados de los poderes de guerra del Gobierno Federal. Asimismo, dejó en claro que

bajo la Constitución y con las garantías que hay establecidas para la protección de la vida, la libertad y la propiedad, el Congreso y el Presidente ejercen el poder bélico de la nación, y tienen amplia discreción en cuanto a los medios que han empleado con éxito para llevar a cabo. Las medidas aquí impugnadas son apoyadas por una fuerte presunción de validez, y que no pueden dejarse de lado a menos que se demuestre claramente que son arbitrarias y repugnantes a la Constitución.

Estas aseveraciones del Justice Butler en el precedente Highland son completamente coherentes con la posición adoptada por la Suprema Corte en varios casos anteriores, los cuales involucraban normas de control de alquileres. En efecto, el Congreso y la Legislatura de Nueva York habían promulgado leyes para paliar la escasez de viviendas en el distrito de Columbia y la ciudad de Nueva York, causada por la movilización de la Primera Guerra Mundial y la correlativa reducción de la construcción de viviendas civiles. La Suprema Corte confirmó ambas medidas, teniendo en cuenta, entre otras cuestiones, que las leyes señaladas incluían una declaración proclamando la existencia de una emergencia que requería el dictado de la mencionada legislación. ${ }^{31}$ Así, Belk-

29 Suprema Corte de los Estados Unidos, Wilson v. New, 243 U.S. 332 (1917).

30 Suprema Corte de los Estados Unidos, Highland v. Russell Car E Snow Plow Co., 279 U.S. 253 (1929).

31 Suprema Corte de los Estados Unidos, Chastleton Corp. v. Sinclair, 264 U.S. 543 (1924), con relación al distrito de Columbia; y Block v. Hirsh, 256 U.S. 135 (1921), con relación a Nueva York. En efecto, 
nap (1983, p. 67) apunta que aquellas emergencias de alguna manera habían ampliado el campo de acción legítima del Gobierno y que la fuente de aquella autoridad adicional era algo más que el poder de la guerra federal.

Por otro lado, cabe destacar que el máximo tribunal norteamericano ha señalado que dado que la circunstancia fáctica de emergencia es la que amplía temporalmente la extensión de la autoridad del Gobierno, si con posterioridad desaparece la situación de emergencia, aquella legislación sería inconstitucional..$^{32}$ Por su parte, en el caso Veix v. Sixth Ward Building,,33 de 1940, la Suprema Corte de los Estados Unidos puntualizó que una ley de emergencia no es inconstitucional, una vez terminada la emergencia, si su contenido pudo dictarse, según la Constitución, como poder permanente.

El Chief Justice Hughes retomó la justificación de las normas de emergencia contenida en el precedente Wilson v. New en el caso Home Building and Loan Association v. Blaisdell, de 1934, en el sentido de que si bien la emergencia no crea un nuevo poder, da ocasión para el ejercicio de un poder. ${ }^{34}$ En sentido con-

teniendo en cuenta ambos casos, se ha dicho que las leyes sobre alquileres de emergencia fueron convalidadas durante y después de la guerra, pero fueron declaradas inválidas una vez que la emergencia finalizó (Field, 1999, p. 166).

$32 \mathrm{Al}$ respecto, cabe remitirse a lo expuesto por el Justice Holmes, emitiendo la opinión de la Suprema Corte en el caso Chastleton Corp. v. Sinclair, 264 U.S. 543 (1924). Con relación al pensamiento de Holmes sobre las emergencias, cabe citar el trabajo de Vermeule (2008), quien pone de relieve que para Holmes, la existencia y la duración de una emergencia es una cuestión judiciable, por lo que los jueces tienen la competencia de declarar que la circunstancia fáctica de emergencia ya no continúa.

33 Suprema Corte de los Estados Unidos, Veix v. Sixth Ward Building $\mathcal{E}$ Loan Ass'n of Newark, 310 U.S. 32 (1940). El Justice Reed emitió la opinión de la Corte y luego de citar diversos casos, entre los que se encontraba Home Building and Loan Association v. Blaisdell, 290 U.S. 398 (1934), destacó: "The cases cited in the preceding paragraph make repeated reference to the emergency existing at the time of the enactment of the questioned statutes. Many of the enactments were temporary in character. We are here considering a permanent piece of legislation. So far as the contract clause is concerned, is this significant? We think not. [Emergency does not create (constitutional) power, emergency may furnish the occasion for the exercise of power.』 We think of emergencies as suddenly arising and quickly passing. The emergency of the depression may have caused the 1932 legislation, but the weakness in the financial system brought to light by that emergency remains. If the legislature could enact the legislation as to withdrawals to protect the associations in that emergency, we see no reason why the new status should not continue".

Con respecto a esta sentencia, Elias (2013, pp. 128-129) aduce que la Suprema Corte norteamericana adoptó un enfoque en el que la ponderación es contextual y global. En efecto, afirma que el consecuencialismo implica que el punto exacto en el que la legislación de emergencia restringe de manera impermisible los derechos de propiedad será siempre móvil e imposible de conocer de antemano.

34 "Emergency does not create power. Emergency does not increase granted power or remove or diminish the restrictions imposed upon power granted or reserved. The Constitution was adopted in a period of grave emergency. Its grants of power to the Federal Government and its limitations of the power of the States were determined in the light of emergency, and they are not altered by emergency. What power was thus granted and what limitations were thus imposed are questions which have 
trario se expresaba el Justice Sutherland en su disidencia en aquel caso, quien entendía que una disposición de la Constitución no podía significar una cosa en un momento dado y otra cosa enteramente distinta en otra.

En este contexto, cabe señalar que quienes apoyaban la legislación del New Deal pretendían utilizar la doctrina de los poderes de emergencia como justificación de aquellas medidas. En efecto, la Ley Nacional de Reconversión de la Industria (National Industrial Recovery Act, NIRA) y la Ley de Ajuste Agrícola (Agricultural Adjustment Act, AAA) contenían declaraciones de una emergencia nacional muy seria, por lo que esta declaración hacía a la gran extensión de regulación económica otorgada al gobierno federal "más aceptable y menos aterradora”. Sin embargo, muchos juristas condenaron que la noción de una emergencia económica podría expandir los poderes constitucionales del Congreso (Belknap, 1983, p. 67). En definitiva, se ha dicho que cuando la Suprema Corte rechazó la Ley Nacional de Reconversión de la Industria (National Industrial Recovery Act), rechazó al mismo tiempo la doctrina de los poderes de emergencia (Vermeule, 2008, p. 166)..$^{35}$

Por otro lado, en relación con el control judicial de otra emergencia, la ley marcial, la Suprema Corte norteamericana señaló que si bien el Ejecutivo tiene amplia discreción para determinar cuándo la emergencia pública es tal como para dar lugar a la necesidad de la declaración de la ley marcial, y su adecuación a la necesidad, ${ }^{36}$ ha mencionado también -en el caso Duncan v. Kahanamoku- ${ }^{37}$ que

always been, and always will be, the subject of close examination under our constitutional system. While emergency does not create power, emergency may furnish the occasion for the exercise of power. Although an emergency may not call into life a power which has never lived, nevertheless emergency may afford a reason for the exertion of a living power already enjoyed."

35 El autor cita el caso A.L.A. Schechter Poultry Corp. v. United States, 295 U.S. 495 (1935), en el cual se indica que "extraordinary conditions do not create or enlarge constitutional power". Más adelante, se hará referencia a este precedente. Al mismo tiempo, indica que aunque después de 1937 la doctrina de los poderes de emergencia no desapareció por completo, fue relegada al segundo escalón de las ideas constitucionales. Volvió a aparecer en contextos económicos o de paz en el derecho constitucional de Estados Unidos, como por ejemplo en el caso National League of Cities v. Usery, 426 U.S. 833 (1976), pero no como un argumento fundamental (cabe destacar que el caso Usery fue revocado por el precedente Garcia v. San Antonio Metropolitan Transit Authority, 469 U.S. 528 (1985)). La doctrina de los poderes de emergencia resultó ser más robusta en contextos relacionados con la guerra y la seguridad nacional en lugar de las emergencias económicas, como las que dieron lugar a las medidas del New Deal. Sin embargo, aduce que, incluso allí, las invocaciones de los poderes de emergencia en algunos casos de notoria seguridad nacional en los años 1940 y 1950, especialmente en el precedente Korematsu v. United States, 323 U.S. 214 (1944), trajeron cierto descredito a esta doctrina.

36 Suprema Corte de los Estados Unidos, Hirabayashi v. United States, 320 U.S. 81 (1943).

37 Suprema Corte de los Estados Unidos, Duncan v. Kahanamoku, 327 U.S. 304 (1946), voto concurrente del Justice Stone. 
la acción ejecutiva no es una prueba de su propia necesidad, y el juicio de los militares aquí no es concluyente de que todas las medidas adoptadas de conformidad con la declaración del estado de guerra haya sido justificada por la exigencia.

En efecto, en el último caso mencionado, se puso de relieve que la ley marcial había sido proclamada el 7 de diciembre de 1941, inmediatamente después del ataque a Pearl Harbor, pero que no cabía ninguna duda de que cuando los peticionarios White y Duncan fueron sometidos a juicios militares el 25 de agosto de 1942 y el 2 de marzo de 1944, respectivamente, se advertía que la situación que había dado lugar a la declaración de la ley marcial ya no subsistía y los tribunales territoriales de Hawái eran perfectamente capaces de ejercer su jurisdicción penal ordinaria. ${ }^{38}$

Por otro lado, y en otro orden de ideas, cabe destacar también el precedente Youngstown Sheet $\mathcal{E}$ Tube Co. v. Sawyer, llamado The Steel Seizure Case, de 1952. En el caso, el presidente Truman había intervenido las fábricas de acero para incrementar la producción y evitar una huelga. Sin embargo, la Suprema Corte declaró la nulidad de tal decisión, estableciendo que ello era competencia del Congreso. ${ }^{39}$ Se ha dicho que el pensamiento de la Suprema Corte norteamericana, en este caso, es que si la Constitución ha asignado al Congreso el poder de tomar ciertas decisiones, ese poder es exclusivo y el presidente carece de poder implícito o inherente para ejercitar por sí tales atribuciones. Asimismo, si el Congreso no ha conferido expresamente el poder que le otorga el artículo I a favor del presidente, es decir, a través de una delegación, ese silencio legislativo debe ser interpretado como prohibición del ejercicio de tales facultades por el Ejecutivo (Bianchi, 1991, p. 141). De acuerdo con la doctrina expuesta, Tribe (1988, p. 239) ha llamado a esta limitación presidencial "los límites silenciosos de los poderes inherentes del Poder Ejecutivo". ${ }^{40}$

38 Ver especialmente el voto concurrente del Justice Murphy.

39 Cabe destacar el voto concurrente del Justice Jackson en relación con el derecho de emergencia: "The appeal, however, that we declare the existence of inherent powers ex necessitate to meet an emergency asks us to do what many think would be wise, although it is something the forefathers omitted. They knew what emergencies were, knew the pressures they engender for authoritative action, knew, too, how they afford a ready pretext for usurpation. We may also suspect that they suspected that emergency powers would tend to kindle emergencies. Aside from suspension of the privilege of the writ of habeas corpus in time of rebellion or invasion, when the public safety may require it, they made no express provision for exercise of extraordinary authority because of a crisis. I do not think we rightfully may so amend their work, and, if we could, I am not convinced it would be wise to do so, although many modern nations have forthrightly recognized that war and economic crises may upset the normal balance between liberty and authority". Un explicación extensa del caso puede encontrarse en Rehnquist (1987). Para un análisis más reciente, ver Swaine (2010).

40 Por su parte, Posner y Vermeule (2007, p. 50) señalan que en realidad en la causa no existía una 
La cuestión sobre las medidas adoptadas durante la emergencia y su validez constitucional se desarrollará más adelante, cuando se analicen los efectos que ha producido la crisis económica de 1929 en la interpretación por parte de la Suprema Corte de la "cláusula contractual" y el "debido proceso" previsto en la Enmienda XIV, donde se destacan precedentes como Home Building and Loan Association v. Blaisdell ${ }^{41}$ y West Coast Hotel v. Parrish. ${ }^{42}$

En este sentido, cabe destacar que el máximo tribunal norteamericano admitió finalmente la constitucionalidad de la legislación del New Deal, entre las cuales se destacan la Ley Nacional de Reconversión de la Industria, la Ley de Ajuste Agrícola y la Ley Nacional de Relaciones Laborales (National Labor Relations Act, NLRA). La doctrina coincide que el New Deal marcó uno de los principales puntos de inflexión en la historia constitucional de Estados Unidos. Cuando Roosevelt asumió el cargo, la Suprema Corte siguió interpretando la Constitución de tal manera que imponía restricciones significativas en la actividad reguladora del gobierno federal. Al final del New Deal, sin embargo, el poder federal sobre asuntos económicos y sociales se había convertido esencialmente ilimitado (Belknap, 1983, p. 67). En efecto, se ha indicado que dos de las grandes innovaciones en la etapa del New Deal ha sido la expansión del Estado regulador (regulatory state) y el cambio de poder de los estados al gobierno federal (Sunstein, 1987, p. 421).

En esta misma línea, Rossiter (1948, p. 264), al referirse al New Deal, sostiene que las emergencias económicas del siglo XX han tenido efectos definitivos y duraderos en el gobierno democrático constitucional. En efecto, considera que las medidas del New Deal adoptadas en 1933 trajeron muchas alteraciones permanentes en la estructura constitucional: importantes delegaciones permanentes del poder de emergencia, ${ }^{43}$ como por ejemplo la "Ley de Emergencia Bancaria” (Emergency Banking Act), una gran expansión de la Administración,

verdadera emergencia. Sostienen: "The Youngstown case, in which the Court invalidated Harry S Truman's order to take control of production at the nation's steel mills to prevent a threatened strike, is a possible example, albeit a slightly muddy one, because the decision came late in a stalemated foreign war (the Korean War) conducted by a deeply unpopular president, rather than in the heat of a genuine emergency".

41 Suprema Corte de los Estados Unidos, Home Building and Loan Association v. Blaisdell, 290 U.S. 398 (1934).

42 Suprema Corte de los Estados Unidos, West Coast Hotel v. Parrish, 300 U.S. 379 (1937).

43 En el mismo sentido, se ha destacado que, a lo largo del tiempo, se han incrementado extensas delegaciones de los poderes de emergencia del Congreso al Presidente (Lobel, 1989, p. 1385). 
una marcada ruptura del principio federal ${ }^{44} \mathrm{y}$ un gran incremento del poder presidencial basado en el liderazgo del Ejecutivo en el proceso legislativo y en la delegación de poder. Así, los años exitosos posteriores del New Deal trajeron consigo estos cambios como permanentes técnicas e instituciones de gobierno.

Estados Unidos ha hecho también una gran utilización de los poderes de emergencia como consecuencia del atentado a las Torres Gemelas el 11 de septiembre de 2001. Una de las medidas más importantes adoptadas para combatir aquella emergencia fue la Ley Patriota (USA Patriot Act). Así, se ha sostenido que si bien fue el Legislativo quien sancionó la norma, lo cierto es que se admitieron muchos poderes extraordinarios al presidente y muchas partes de la ley eran controvertidas (Scheppele, 2006, pp. 231-232). En efecto, los atentados terroristas llevaron a que hubiera una gran discusión respecto a los alcances de los poderes del presidente. La Suprema Corte norteamericana se expidió en tres casos resueltos el 28 de junio de 2004, reconociendo el derecho a acceder a un tribunal a aquellos que se encontraban detenidos por ser considerados parte de la guerra contra el terrorismo. ${ }^{45}$

Finalmente, cabe precisar que el presidente Donald Trump ha declarado la emergencia nacional concerniente a la pandemia del Covid-19 a través de la Proclamación 9994 del 13 de marzo de 2020, sustentándose, entre otras, en la Ley de Emergencias Nacionales (National Emergencies Act). También ha dictado medidas apoyándose en la Ley Stafford de Ayuda ante Desastres y Asistencia de Emergencia (Robert T. Stafford Disaster Relief and Emergency Assistance Act), la cual diseñó de manera sistemática el modo de interacción entre el gobierno federal y los gobiernos estatales y locales ante una emergencia.

En relación con el alcance de la actuación judicial en situaciones de emergencia, se ha dicho muy gráficamente que si se da una situación de crisis nacional, los jueces "tienden a ir a la guerra" (Belknap, 1980, p. 59). Así, en situaciones de emergencia, los tribunales asumen una actitud altamente deferencial cuando se trata de revisar acciones y decisiones gubernamentales (Gross y Ní

44 Del mismo modo, se ha dicho que la Suprema Corte, durante la etapa del New Deal, reescribió la historia del derecho constitucional y modificó de forma permanente la expansión de los poderes federales. Al respecto, ver Roots (2000, p. 259 y ss).

45 Estos casos son Hamdi v. Rumsfeld, 542 U.S. 507 (2004); Rumsfeld v. Padilla, 542 U.S. 426 (2004); y Rasul v. Bush, 542 U.S. 466 (2004). Cabe destacar también el caso Boumediene v. Bush, 553 U.S. 723 (2008), en el cual la Suprema Corte norteamericana declaró inconstitucional la denegación del hábeas corpus a quienes no fueran ciudadanos y estuvieran retenidos como combatientes enemigos. Sobre las tres primeras sentencias, ver el comentario de Frosini (2006). A su vez, sobre los poderes del presidente en la guerra contra el terrorismo, ver Chemerinsky (2015, pp. 560-570). 
Aoláin, 2006, p. 78). En el mismo sentido, Rossiter (1984) señala que la Suprema Corte pareciera ser un "observador bastante inofensivo" de las decisiones que adoptan el Congreso y el Poder Ejecutivo para combatir una emergencia. Por su parte, Posner y Vermeule (2007) describen de este modo la deferencia de los jueces ante las situaciones de emergencia: "Cuando una emergencia tiene lugar, el Ejecutivo actúa, el Congreso consiente, y los tribunales son deferentes. Cuando la emergencia entra en decadencia, los jueces se vuelven más audaces y la búsqueda del alma comienza" (p. 3).

Por otro lado, cabe destacar que si bien durante todas las guerras de los Estados Unidos la Constitución ha permanecido vigente y no ha guardado silencio en esas situaciones, se ha dicho que indudablemente, en algunas cuestiones, habla de modo más apagado, en tonos más equívocos que en tiempos de paz (Falon Jr., 2013, p. 333). Esta situación trae a colación lo expuesto por el Chief Justice Marshall en el caso McCullock v. Maryland, en el cual expuso que la Constitución había sido diseñada para ser adaptable a las diversas crisis de los asuntos humanos. ${ }^{46} \mathrm{~A}$ su vez, cabe señalar que sin perjuicio de que los jueces adopten una actitud deferente en casos de emergencia con relación a las medidas adoptadas por el Gobierno, esto no implica que el ejercicio de tales facultades no tenga límites. En este sentido, cabe resaltar lo expresado por el Justice O'Connor en el caso Hamdi v. Rumsfeld, donde expresó que el estado de guerra "no es un cheque en blanco para el Presidente". ${ }^{47}$

\section{Constituciones europeas}

\subsection{Alemania}

La Ley Fundamental de Bonn, de fecha 8 de mayo de 1949, omitió prever las distintas situaciones excepcionales que podían permitir la suspensión del ejercicio de determinados derechos (León Zaa, 2014, p. 112). Con posterioridad, el estado

46 Suprema Corte de los Estados Unidos, McCulloch v. Maryland, 17 U.S. 316 (1819). En efecto, en el precedente citado se expresó lo siguiente: "This provision is made in a Constitution intended to endure for ages to come, and consequently to be adapted to the various crises of human affairs. To have prescribed the means by which Government should, in all future time, execute its powers would have been to change entirely the character of the instrument and give it the properties of a legal code. It would have been an unwise attempt to provide by immutable rules for exigencies which, if foreseen at all, must have been seen dimly, and which can be best provided for as they occur. To have declared that the best means shall not be used, but those alone without which the power given would be nugatory, would have been to deprive the legislature of the capacity to avail itself of experience, to exercise its reason, and to accommodate its legislation to circumstances".

47 Suprema Corte de los Estados Unidos, Hamdi v. Rumsfeld, 542 U.S. 507 (2004). 
de excepción tuvo una amplia reglamentación en la enmienda introducida en la Constitución el 24 de junio de 1968, por lo que se modificó de forma decisiva la situación constitucional de la República Federal de Alemania. De este modo, la nueva legislación de emergencia agregó, modificó o eliminó veintiocho artículos constitucionales. Asimismo, se dictaron, entre 1965 y 1968, "leyes simples de emergencia" que contienen alrededor de trescientos artículos (Schneider, 1999, p. 114).

De este modo, se ha señalado que se dificulta tener un cuadro confiable de la situación jurídica de la cuestión, no solo por el volumen de las normas como por la complicada técnica legislativa en atención a las numerosas referencias. Asimismo, teniendo en cuenta lo expuesto, se ha diferenciado, si bien no surge expresamente en el ordenamiento,

las disposiciones objetivas para el caso de una situación de emergencia externa e interna, así como disposiciones tales que han surgido dentro del marco de la legislación de emergencia, pero que no contienen Derecho de emergencia o solo de forma limitada. (Schneider, 1999, pp. 114-115)

Así, por un lado, se prevén casos de emergencia externa, que es el supuesto del llamado "caso de defensa" a causa de un ataque armado de fuerzas extranjeras. Por otro lado, se prevén casos de emergencia interna para los casos de catástrofes naturales, de accidentes muy graves, así como peligros que amenacen la permanencia de la Federación, de un Estado Federado o del ordenamiento constitucional democrático-liberal. Pero es dable destacar que, en estos dos últimos casos, "no se ha previsto una determinación o proclamación del Estado de Emergencia” (Schneider, 1999, pp. 114-115). En este contexto, cabe resaltar de forma particular los siguientes institutos: ${ }^{48}$

1. El "mecanismo de ayuda" en caso de catástrofes naturales y especialmente en caso de accidentes graves previsto en el artículo 35, apartados 2 y 3 . Sobre este aspecto, cabe resaltar que la última parte del apartado 3 indica que las medidas adoptadas del Gobierno Federal se suspenderán en cualquier momento a petición del Bundesrat [Consejo Federal] y, en cualquier caso, "sin demora alguna después de haber sido conjurado el peligro".

2. El estado de emergencia interior estipulado en el artículo 91, que tiene lugar para "la defensa contra un peligro que amenace la existencia del régimen fundamental de libertad y democracia de la Federación o de un Land”.

48 Las citas de la Ley Fundamental de Alemania corresponden a la traducción efectuada por García Macho y Sommermann (2010). 
3. El artículo 81.a establece la aplicación de determinadas disposiciones jurídicas "en caso de tensión". 49

4. El capítulo X.a establece el "caso de defensa". Se determina en su artículo 115.a.1 que

[l]a declaración de que el territorio federal es objeto de una agresión armada o que una agresión tal es inminente (caso de defensa) la hará el Bundestag [Parlamento Federal] con la aprobación del Bundesrat. Dicha declaración se hará a petición del Gobierno Federal y requiere una mayoría de dos tercios de los votos emitidos y, como mínimo, la mayoría de los miembros del Bundestag. ${ }^{50}$

\section{Por su parte, el artículo 115.1.2, en lo que respecta a la finalización del caso} de defensa, indica que

[e]l Bundestag, con la aprobación del Bundesrat, podrá declarar en cualquier momento, mediante una decisión que deberá ser promulgada por el Presidente Federal, la terminación del caso de defensa. El Bundesrat podrá exigir que el Bundestag adopte una decisión a este respecto. Deberá declararse la terminación del caso de defensa tan pronto como hubieren desaparecido las condiciones que dieron lugar a su declaración.

5. El "estado de necesidad legislativa" del artículo 81 de la Constitución alemana, en la cual se permite la adopción de medidas de urgencia. Sin embargo, se ha dicho que se trata de una fórmula excepcional, muy limitada y de difícil utilización, tanto que no se ha utilizado nunca en la práctica (Aragón Reyes, 2016, p. 19).

49 El artículo 80.a establece: "Cuando en la presente Ley Fundamental o en una ley federal sobre la defensa, con inclusión de la protección de la población civil, se establezca que determinadas disposiciones jurídicas no pueden ser aplicadas más que con arreglo a lo establecido en el presente artículo, no estará permitida la aplicación de las mismas fuera del caso de defensa a menos que el Bundestag constate la existencia del caso de tensión cuando apruebe expresamente su aplicación. La comprobación del caso de tensión y la aprobación expresa en los casos previstos en el artículo 12a, apartado 5 , frase 1 , y apartado 6, frase 2, requieren una mayoría de dos tercios de los votos emitidos [...]".

50 Este instituto posee una extensa regulación. En efecto, además de las disposiciones del artículo 115.a -que prevé el concepto y la declaración del caso de defensa-, en el artículo 115.b se establece la transferencia al canciller federal de la jefatura y del mando de las Fuerzas Armadas; en el artículo 115.c, la competencia legislativa ampliada de la Federación; en el artículo 115.d, el procedimiento legislativo aplicable a los proyectos urgentes de ley; en el artículo 115.e, las atribuciones de la Comisión Conjunta; en el artículo 115.f, las atribuciones del Gobierno Federal; en el artículo 115.g, la posición de la Corte Constitucional Federal; en el artículo 115.h, el funcionamiento de los órganos constitucionales; en el artículo 115.i, las atribuciones de los Gobiernos de los Länder; en el artículo 115.k, la duración de la vigencia de las medidas jurídicas excepcionales; y en el artículo 115.1, la derogación de las leyes y medidas extraordinarias, la terminación del caso de defensa y la conclusión de la paz. 
Finalmente, cabe señalar que el artículo 20 establece los fundamentos del orden estatal, precisando que "la República Federal de Alemania es un Estado federal democrático y social” (apartado 1) y que "[e]l poder legislativo está sometido al orden constitucional; los poderes ejecutivo y judicial, a la ley y al Derecho". Seguidamente, en el apartado 4 se establece el derecho de resistencia: "[c]ontra cualquiera que intente eliminar este orden todos los alemanes tienen el derecho de resistencia cuando no fuere posible otro recurso". Este derecho de resistencia, se ha indicado, es como un último recurso a utilizar para la defensa del orden democrático-liberal de la Ley Fundamental, por lo que se establece un derecho a la resistencia en relación con la legislación de emergencia (Schneider, 1999, p. 116).

\subsection{España}

El ordenamiento constitucional español de 1978, señala Cruz Villalón (1984, p. 47), ha adoptado el modelo de derecho de excepción "clásico" en el Estado de derecho, basado en la previsión, ante el supuesto de una situación de emergencia, de una serie de modificaciones puntuales y concretas respecto a la vigencia ordinaria de la Constitución, esto es, un estado excepcional. El autor indica que este derecho de excepción se diversifica en una pluralidad de estados excepcionales, cada uno de ellos vinculado a un tipo específico de emergencia, los cuales son los estados de alarma, de excepción y de sitio.

Dentro del título primero ("De los derechos y deberes fundamentales"), capítulo quinto ("De la suspensión de los derechos y libertades") de la Constitución Española, se encuentra el artículo 55, que en su primer apartado regula la suspensión colectiva de los derechos individuales. Esta norma establece que diversos derechos reconocidos en la Constitución Española ${ }^{51}$ pueden ser suspendidos cuando se acuerde la declaración del estado de excepción o de sitio en los términos previstos en la Constitución. ${ }^{52}$

Así, el artículo 116.1 de la Constitución Española prevé tres situaciones: estados de alarma, de excepción y de sitio, estableciendo que una ley orgánica regulará las competencias y limitaciones correspondientes. La ley orgánica que

51 Se refiere a los previstos en los artículos $17 ; 18$, apartados 2 y $3 ; 19 ; 20$, apartados 1 a) y d), y $5 ; 21$; 28, apartado 2; y 37, apartado 2 CE.

52 A su vez, indica que en el supuesto de declaración de estado de excepción, se exceptúa de lo establecido anteriormente el apartado 3 del artículo $17 \mathrm{CE}$. No se hará referencia a la suspensión individual de los derechos individuales. Sobre el punto, ver Martínez Cuevas (2002). 
regula la cuestión es la 4/1981, la cual, en su artículo 1, de modo general determina que procede la declaración de los estados de alarma, excepción o sitio cuando "circunstancias extraordinarias hiciesen imposible el mantenimiento de la normalidad mediante los poderes ordinarios de las autoridades competentes".

Sobre el particular, la doctrina indica que el estado de alarma es un estado excepcional concebido sustancialmente frente a las catástrofes naturales y accidentes de gran magnitud. El estado de excepción es el estado excepcional civil previsto frente a situaciones de grave alteración del orden público. Finalmente, el estado de sitio, como estado de excepción militar, está previsto para aquellas situaciones extremas en las que está en juego directamente la supervivencia del Estado como Estado soberano y su ordenamiento constitucional (Cruz Villalón, 1984, p. 52).

Estado de alarma. El artículo 116.2 de la Constitución Española se refiere al estado de alarma, estableciendo que será declarado por el Gobierno mediante decreto acordado en Consejo de Ministros por un plazo máximo de quince días, dando cuenta al Congreso de los Diputados, quien debe reunirse inmediatamente al efecto y sin cuya autorización no podrá ser prorrogado dicho plazo. La norma afirma que el decreto debe determinar el ámbito territorial al que se extienden los efectos de la declaración.

En cuanto a las situaciones que pueden dar lugar a la declaración del estado de alarma por parte del Gobierno, la ley orgánica establece que deben producirse alguna de las siguientes
alteraciones graves de la normalidad: a) Catástrofes, calamidades o desgracias pú- blicas, tales como terremotos, inundaciones, incendios urbanos y forestales o acci- dentes de gran magnitud. b) Crisis sanitarias, tales como epidemias y situaciones de contaminación graves. c) Paralización de servicios públicos esenciales para la comunidad, cuando no se garantice lo dispuesto en los artículos 28.2 [derecho a la huelga] y 37.2 [derecho a adoptar medidas de conflicto colectivo] de la Constitu- ción, y concurra alguna de las demás circunstancias o situaciones contenidas en este artículo. d) Situaciones de desabastecimiento de productos de primera necesidad.

Al respecto, el Tribunal Constitucional ha sostenido que, a diferencia de los estados de excepción y de sitio, la declaración del estado de alarma no permite la suspensión de ningún derecho fundamental, aunque sí la adopción de medidas que pueden suponer limitaciones o restricciones a su ejercicio. ${ }^{53}$

53 Sentencia del Tribunal Constitucional, 83/2016, del 28 de abril, Fundamento Jurídico 8. 
Desde la sanción de la Constitución de 1978, el Gobierno recurrió a esta figura en dos oportunidades. La primera de ellas, al dictar el Decreto 1673/2010, por el que se declaró el estado de alarma para la normalización del servicio público esencial del transporte aéreo, y el Decreto 1717/2010, por el que se prorrogó el estado de alarma declarado por el decreto antes citado. La promulgación del estado de alarma se debió a la situación laboral de los controladores civiles del tráfico aéreo. El Gobierno justificó la medida en virtud del artículo 19 del texto constitucional español con relación a la libre circulación. El Congreso de los Diputados, mediante acuerdo del Pleno de 16 de diciembre de 2010, autorizó la prórroga del estado de alarma. Los controladores del tráfico aéreo recurrieron en amparo aquella prórroga, pero el Tribunal Constitucional en el Auto 7/2012 consideró que era inadmisible el recurso de amparo.

La segunda oportunidad en que fue declarado el estado de alarma fue a través del Decreto 463/2020, del 14 de marzo, con el fin de afrontar la situación de emergencia sanitaria provocada por el Covid-19, el cual fue prorrogado en distintas oportunidades. Al respecto, cabe señalar que la Sala Primera del Tribunal Constitucional, mediante Auto del 30 de abril, no admitió un recurso de amparo contra la sentencia que había desestimado una demanda interpuesta por un sindicato para poder manifestarse el día del trabajador. El tribunal consideró que no se daban las circunstancias que permitieran el ejercicio del derecho de reunión por la situación de pandemia. Sostuvo que la relación entre el derecho a la vida y el de reunión exigía una ponderación por la que, ante la falta de las garantías de seguridad en una situación de máximo contagio, debía primar el primer derecho..$^{54}$

Estado de excepción. El artículo 116.3 de la Constitución española indica que debe ser declarado por el Gobierno mediante decreto acordado en Consejo de Ministros, previa autorización del Congreso de los Diputados. La norma establece que la autorización y proclamación del estado de excepción debe determinar expresamente los efectos de este, el ámbito territorial al que se extiende y su duración, el cual no podrá exceder de treinta días, siendo dicho plazo prorrogable por otro plazo igual con los mismos requisitos.

El artículo 13.1. de la Ley Orgánica 4/1981 precisa que el Gobierno puede solicitar al Congreso de los Diputados autorización para declarar el estado de excepción cuando

$54 \mathrm{Al}$ respecto, ver especialmente el Fundamento Jurídico 4. 
el libre ejercicio de los derechos y libertades de los ciudadanos, el normal funcionamiento de las instituciones democráticas, el de los servicios públicos esenciales para la comunidad, o cualquier otro aspecto del orden público, resulten tan gravemente alterados que el ejercicio de las potestades ordinarias fuera insuficiente para restablecerlo y mantenerlo.

Estado de sitio. El artículo 116.4 de la Constitución Española indica que debe ser declarado por la mayoría absoluta del Congreso de los Diputados, a propuesta exclusiva del Gobierno, debiendo el Congreso determinar su ámbito territorial, duración y condiciones. Por su parte, el artículo 32 de la Ley Orgánica 4/1981 establece que el Gobierno puede proponer al Congreso de los Diputados la declaración de estado de sitio cuando "se produzca o amenace producirse una insurrección o acto de fuerza contra la soberanía o independencia de España, su integridad territorial o el ordenamiento constitucional, que no pueda resolverse por otros medios".

Por otro lado, cabe destacar que la Constitución admite que el Gobierno pueda dictar decretos-leyes. Sobre el punto, el artículo 86.1 indica que

[e]n caso de extraordinaria y urgente necesidad, el Gobierno podrá dictar disposiciones legislativas provisionales que tomarán la forma de Decretos-leyes y que no podrán afectar al ordenamiento de las instituciones básicas del Estado, a los derechos, deberes y libertades de los ciudadanos regulados en el Título I, al régimen de las Comunidades Autónomas, ni al Derecho electoral general.

Al respecto, el Tribunal Constitucional ha rechazado la aproximación del instituto del decreto-ley al derecho de excepción, al destacar que la extraordinaria y urgente necesidad "no ha de entenderse en el sentido extremo de confiar el Decreto-ley para ordenar situaciones -o intervenir en acontecimientos- de excepcional amenaza para la comunidad o el orden constitucional". ${ }^{55}$ En efecto, el tribunal ha destacado que la necesidad justificadora de los decretos-leyes no puede entenderse como una necesidad absoluta que suponga un peligro grave para el sistema constitucional o para el orden público, entendido como normal ejercicio de los derechos fundamentales y libertades públicas y normal funcionamiento de los servicios públicos, sino que hay que entenderlo con mayor amplitud como necesidad relativa. ${ }^{56}$

En el mismo sentido, la doctrina ha señalado que los supuestos excepcio-

55 Sentencia del Tribunal Constitucional, 111/1983, del 2 de diciembre, Fundamento Jurídico 6.

56 Sentencia del Tribunal Constitucional, 6/1983, del 4 de febrero, Fundamento Jurídico 5. 
nales a los que debe hacer frente el decreto-ley no son equiparables a las previsiones del artículo 116 del texto constitucional español (Carmona Contreras, 1997; Garrorena Morales, 2014, p. 213; Ylarri, 2019b, pp. 59-60). En particular, De Otto (1988, p. 197) destaca que el presupuesto habilitante no es ninguno de los instrumentos excepcionales del artículo 116 de la Constitución española, sino "una anormalidad de tono menor".

\subsection{Francia}

La Constitución de Francia de 1958 concede al presidente de la República un conjunto de facultades extraordinarias, que fueron denominadas por Andrè Hauriou (1980, p. 627) como "el ejercicio de una dictadura temporal en período de urgencia”.

De este modo, el artículo 5, en su primer párrafo, dispone que el presidente de la República "velará por el respeto a la Constitución y asegurará, mediante su arbitraje, el funcionamiento regular de los poderes públicos, así como la permanencia del Estado". Ahora bien, el artículo 16 determina que cuando "las instituciones de la República, la independencia de la Nación, la integridad de su territorio o el cumplimiento de sus compromisos internacionales estén amenazados de manera grave o inmediata y el funcionamiento regular de los poderes públicos constitucionales esté interrumpido”, el presidente de la República debe tomar las medidas exigidas por tales circunstancias, previa consulta oficial con el primer ministro, los presidentes de las Cámaras y el Consejo Constitucional. Las medidas que adopte deben "estar inspiradas por la voluntad de garantizar a los poderes públicos constitucionales, en el menor plazo, los medios para cumplir su misión” y el Consejo Constitucional será consultado sobre ello.

El último párrafo del mencionado artículo establece una consulta al Consejo Constitucional. En efecto, señala que tras treinta días de ejercicio de los poderes excepcionales,

el Consejo Constitucional podrá ser solicitado por el Presidente de la Asamblea Nacional, el Presidente del Senado, sesenta diputados o sesenta senadores, a efectos de examinar si se siguen cumpliendo las condiciones enunciadas en el primer párrafo. Se pronunciará lo antes posible mediante anuncio público. Procederá de pleno derecho a este examen y se pronunciará en las mismas condiciones al término de sesenta días de ejercicio de los poderes excepcionales y en cualquier momento pasado este plazo. 
De este modo, se ha dicho que para que el presidente pueda ejercer el mencionado instituto, se necesita la confluencia de un par de circunstancias de hecho: (a) que se aprecie la grave e inminente amenaza de las instituciones de la República, la independencia del Estado francés, la intangibilidad de su territorio o el cumplimiento de sus compromisos internacionales; y (b) que se observe la circunstancia que lleve consigo la interrupción del funcionamiento normal de los poderes públicos constitucionales. A su vez, cabe precisar que es al presidente al que le corresponde evaluar si se dan las situaciones de hecho, no teniendo fuerza vinculante las consultas previas al primer ministro, presidente del Senado, presidente de la Asamblea Nacional y Consejo Constitucional (León Zaa, 2014, pp. 111-112).

Finalmente, el artículo 36 de la Constitución francesa establece que el estado de sitio debe ser decretado por el Consejo de Ministros y que su prórroga después de doce días solo podrá ser autorizada por el Parlamento.

\subsection{Italia}

En lo que respecta al caso italiano, el artículo 13 de la Constitución indica que si bien la libertad personal es inviolable, en

casos excepcionales de necesidad y de urgencia, especificados taxativamente en la ley, la autoridad de orden público podrá adoptar medidas provisionales que deberán ser comunicadas dentro de las cuarenta y ocho horas siguientes a la autoridad judicial y que, de no ser confirmadas por ésta en las cuarenta y ocho horas subsiguientes, se considerarán revocadas y no surtirán efecto alguno.

A su vez, la Constitución italiana prevé la situación de guerra, indicándose en su artículo 78 que la Cámara de Diputados y la Cámara de Senadores "acordarán el estado de guerra y conferirán al Gobierno los poderes necesarios”.

Por otro lado, cabe destacar de forma especial la potestad del Gobierno de dictar decretos que tengan fuerza de ley en casos extraordinarios de necesidad y urgencia. En este sentido, el artículo 77 establece que, en principio, el Gobierno no puede dictar decretos que tengan fuerza de ley ordinaria, salvo en "casos extraordinarios de necesidad y de urgencia”. La mencionada norma dispone:

No podrá el Gobierno, sin delegación de las Cámaras, dictar decretos que tengan fuerza de ley ordinaria. Cuando en casos extraordinarios de necesidad y de urgencia (in casi straordinari di necessità e urgenza) el Gobierno adopte, bajo su res- 
ponsabilidad, medidas provisionales con fuerza de ley, deberá presentarlas el día mismo para su conversión a las Cámaras, las cuales, incluso hallándose disueltas, serán debidamente convocadas y se reunirán dentro de los cinco días siguientes. Los decretos perderán todo efecto desde el principio si no fueren convertidos en ley dentro de los sesenta días de su publicación. Las Cámaras podrán, sin embargo, regular mediante ley las relaciones jurídicas surgidas en virtud de los decretos que no hayan resultado convertidos.

En relación con el presupuesto que habilita el dictado de estos decretos, la doctrina ha puesto de manifiesto que debe presentarse una situación extraordinaria, la cual no pueda ser afrontada con los instrumentos ya previstos. A su vez, se afirma que deben concurrir tanto la necesidad -la intervención debe ser inevitable- y la urgencia, es decir, que la intervención no pueda ser pospuesta (Bin y Pitruzzella, 2009, p. 351; De Vergottini, 2010, p. 207).

En sus comienzos, la Corte Constitucional italiana tuvo un abierto rechazo a controlar este tipo de normas. Luego, reconoció su facultad fiscalizadora sobre la constitucionalidad de la valoración política llevada a cabo por el Gobierno y el Parlamento con relación a situaciones de extraordinaria y urgente necesidad, dando razón a una generalizada opinión de la doctrina en ese sentido (Carmona Contreras, 1997, p. 64). Así, se ha sostenido que la prohibición de reiteración de los decretos-leyes "ha ocurrido gracias a la labor de la Corte Constitucional, que ha puesto un freno en las reiteraciones" (Castro E Caramago, 2011; Celotto, 2002). En efecto, la Corte Constitucional italiana, en su jurisprudencia, ha establecido que puede verificar la existencia de una "evidente carencia" de los presupuestos de necesidad y urgencia. Sobre el punto, adujo que

[1]a preexistencia de una situación de hecho que comporte la necesidad de la utilización de un instrumento excepcional como el decreto-ley, constituye un requisito de validez constitucional de la adopción de dicha disposición, de manera que la eventual evidente carencia de ese presupuesto constituye en primer término un vicio de inconstitucionalidad del decreto-ley adoptado fuera de su ámbito de aplicación constitucionalmente previsto. ${ }^{57}$

\section{Límites a los institutos de excepción y los alcances de su control}

Con relación a la temática objeto de la presente investigación, del análisis de las

57 Sentencia de la Corte Constitucional, 128/2008, Fundamento Jurídico 8.1. En el mismo sentido, ver la sentencia 171/2007. 
constituciones citadas pueden puntualizarse diversas cuestiones que se detallan a continuación.

\section{1. Órgano competente para declarar el instituto de excepción}

La mayoría de las constituciones analizadas establecen que el acto declarativo del instituto de excepción es efectuado por el órgano Ejecutivo y sujeto a la aprobación del órgano Legislativo. ${ }^{58}$ En algunos casos, como en Estados Unidos, en nuestro país -a los efectos de declarar el estado de sitio en caso de conmoción interior- o en Alemania -por ejemplo, en el caso de defensa-, corresponde al Congreso.

A su vez, en otros supuestos, se prevé la intervención del órgano Legislativo en caso de que se prorrogue la situación de excepción. De este modo, la Constitución chilena requiere que en el caso de sucesivas prórrogas del estado de emergencia, el presidente solicite "siempre del acuerdo del Congreso Nacional"; ${ }^{59}$ en Colombia, en caso de conmoción interior, la segunda prórroga "requiere concepto previo y favorable del Senado de la República"; ${ }^{60}$ en Perú, para la prórroga del estado de sitio se requiere la aprobación del Congreso; $;^{61} \mathrm{y}$ en España se establece que el plazo de vigencia del estado de alarma no puede ser prorrogado sin la autorización del Congreso de los Diputados. ${ }^{62}$ Finalmente, en Venezuela se determina que "la aprobación de la prórroga de los estados de excepción corresponde a la Asamblea Nacional”. ${ }^{63}$

\subsection{Limitación temporal del instituto de excepción}

Las disposiciones constitucionales de los diversos países analizados, al regular los estados de excepción, establecen su duración limitada en el tiempo y, en muchas ocasiones, se determinan plazos específicos.

La Constitución de Brasil dispone de modo genérico que las medidas que se

58 Artículo 137 de la Constitución de Bolivia; artículos 136 y 137 de la Constitución de Brasil; artículo 40 de la Constitución de Chile; artículo 339 de la Constitución de Venezuela; artículo 115 de la Constitución de Alemania; artículo 116 de la Constitución de España; y artículo 36 de la Constitución de Francia.

59 Constitución de Chile, artículo 42.

60 Constitución de Colombia, artículo 213.

61 Constitución de Perú, artículo 137.2.

62 Constitución de España, artículo 116.2.

63 Constitución de Venezuela, artículo 339. 
adopten deben restablecer el orden público o la paz social en "breve tiempo", ${ }^{64}$ así como que los decretos que establezcan la medida de emergencia deben determinar o indicar el tiempo de su duración. ${ }^{65}$ A continuación, determina un plazo específico de duración del estado de sitio: no puede decretarse por más de "treinta días, que no puede prorrogarse, de cada vez, por plazo superior". ${ }^{66}$

Del mismo modo, la Constitución de Chile establece que la declaración del estado de sitio "sólo podrá hacerse por un plazo de quince días, sin perjuicio de que el Presidente de la República solicite su prórroga". ${ }^{67}$ En Colombia, se prevé que el estado de conmoción interior puede ser declarado "por término no mayor de noventa días, prorrogable hasta por dos períodos iguales" ${ }^{68} \mathrm{En}$ el caso del estado de emergencia, puede ser declarado "por períodos hasta de treinta días en cada caso, que sumados no podrán exceder de noventa días en el año calendario", y que "el Gobierno, en el decreto que declare el Estado de Emergencia, señalará el término dentro del cual va a hacer uso de las facultades extraordinarias". ${ }^{69}$ La Constitución ecuatoriana determina que el estado de excepción tiene una vigencia máxima de sesenta días, pudiéndose renovar por treinta días más si persisten las causas que lo motivaron. ${ }^{70}$ En el caso de Paraguay, puede declararse el estado de excepción "por un término de sesenta días como máximo. [...] Dicho término de sesenta días podrá prorrogarse por períodos de hasta treinta días sucesivos”. Finalmente, Venezuela prevé también plazos específicos para los institutos de excepción previstos en su norma fundamental. Así, la duración del estado de alarma es de hasta treinta días, prorrogable por treinta días más; la del estado de emergencia económica, hasta sesenta días, prorrogables por un plazo igual; y el estado de conmoción interior o exterior se prolonga hasta por noventa días, siendo prorrogable hasta por noventa días más. ${ }^{71}$

La Constitución de México no establece una duración específica del instituto de excepción, pero habilita a suspender las garantías que fuesen obstáculo para hacer frente, rápida y fácilmente a la situación, "pero deberá hacerlo por

\footnotetext{
64 Constitución de Brasil, artículo 136.

65 Constitución de Brasil, artículos 136 y 138.

66 Constitución de Brasil, artículo 138.

67 Constitución de Chile, artículo 40.

68 Constitución de Colombia, artículo 213.

69 Constitución de Colombia, artículo 215.

70 Constitución de Ecuador, artículo 166.

71 Constitución de Venezuela, artículo 338.
} 
un tiempo limitado". ${ }^{72}$ De este modo, corresponde destacar también que algunas constituciones, si bien prevén un límite temporal para ciertas situaciones de excepción, no fijan un plazo concreto. En efecto, la Constitución de Brasil indica que la declaración de estado de guerra o respuesta a una agresión armada extranjera podrá ser decretada por todo el tiempo que perdurase la guerra o la agresión armada extranjera. ${ }^{73}$ La Constitución chilena señala que el estado de asamblea mantendrá su vigencia "por el tiempo que se extienda la situación de guerra exterior, salvo que el Presidente de la República disponga su suspensión con anterioridad". ${ }^{74}$ La Constitución francesa estipula que las medidas a adoptar deben llevarse a cabo "en el menor plazo". ${ }^{75}$ Finalmente, la Constitución alemana, en relación con el mecanismo de ayuda en caso de catástrofes naturales y especialmente en caso de accidentes graves, establece que las medidas del Gobierno Federal adoptadas deben suspenderse "sin demora alguna después de haber sido conjurado el peligro". ${ }^{76}$

\subsection{Deber de motivar la existencia de la circunstancia fáctica excepcional}

Otra cuestión trascendente es que en la declaración del instituto de excepción el órgano correspondiente debe expresar los motivos por los cuales se declara la medida. En efecto, en Brasil, al solicitarse autorización para decretar el estado de sitio o su prórroga, el presidente de la República "señalará los motivos determinantes de la solicitud" ; ${ }^{77}$ en Colombia, se requiere que la declaración del estado de emergencia sea "motivada"; 78 en Paraguay, la declaración del estado de excepción debe contener "las razones y los hechos que se invoquen para su adopción”; ${ }^{79}$ finalmente, en México, se exige que la restricción o suspensión del ejercicio de los derechos y garantías debe estar "fundada y motivada". 80

72 Constitución de México, artículo 29.

73 Constitución de Brasil, artículo 138.

74 Constitución de Chile, artículo 40.

75 Constitución de Francia, artículo 16.

76 Constitución de Alemania, artículo 35.3.

77 Constitución de Brasil, artículo 137.

78 Constitución de Colombia, artículo 215.

79 Constitución de Paraguay, artículo 288.

80 Constitución de México, artículo 29. 


\subsection{Control del órgano legislativo sobre las causas que motivaron el dictado del instituto de excepción}

Algunas constituciones prevén explícitamente que el órgano Legislativo puede dejar sin efecto la declaración de emergencia efectuada por el órgano Ejecutivo si cesan las causas que lo motivaron.

En efecto, en Chile, con relación al estado de catástrofe, se establece que "el Congreso Nacional único podrá dejar sin efecto la declaración transcurridos ciento ochenta días desde ésta si las razones que la motivaron hubieran cesado en forma absoluta". ${ }^{81}$ La Constitución paraguaya indica que el Congreso, por mayoría absoluta de votos, puede disponer en cualquier momento el levantamiento del estado de excepción, "si considerase que cesaron las causas de su declaración”. ${ }^{82}$ Por su parte, la Constitución ecuatoriana prevé que si las circunstancias lo justifican, "la Asamblea Nacional podrá revocar el decreto en cualquier tiempo". ${ }^{83}$ También la Constitución de Venezuela determina que si cesan las causas que lo motivaron, la declaración del instituto de excepción debe ser dejada sin efecto. En esta línea, el presidente de la República "puede solicitar su prórroga por un plazo igual, y será revocado por el Ejecutivo Nacional o por la Asamblea Nacional o por su Comisión Delegada, antes del término señalado, al cesar las causas que lo motivaron". ${ }^{84}$

\subsection{El control de constitucionalidad de la declaración}

En lo que respecta al control judicial de las declaraciones de emergencia, en general se guarda silencio sobre el tema.

Algunas constituciones prevén expresamente la intervención del órgano encargado de controlar la constitucionalidad de la norma. En efecto, la Constitución ecuatoriana establece la obligación de notificar la declaración del estado de excepción, entre otros, a la Corte Constitucional, quien se debe pronunciar sobre su constitucionalidad. ${ }^{85} \mathrm{~A}$ su vez, en Venezuela, se estipula que el decreto que declare el estado de excepción debe ser presentado dentro de los ocho días siguientes a su promulgación, entre otros, "a la Sala Constitucional del Tribu-

\footnotetext{
81 Constitución de Chile, artículo 41.

82 Constitución de Paraguay, artículo 288.

83 Constitución de Ecuador, artículo 166.

84 Constitución de Venezuela, artículo 339.

85 Constitución de Ecuador, artículo 166.
} 
nal Supremo de Justicia, para que se pronuncie sobre su constitucionalidad". ${ }^{86}$ Asimismo, la Constitución de Colombia estipula que el Gobierno debe enviar a la Corte Constitucional, al día siguiente de su expedición, los "decretos legislativos" que dicte en el marco de un estado de emergencia, para que aquella decida sobre su constitucionalidad. ${ }^{87}$ Por último, el texto constitucional mexicano determina que los decretos expedidos por el Ejecutivo durante la restricción o suspensión, deben ser revisados de oficio e inmediatamente por la Suprema Corte de Justicia de la Nación, la cual debe pronunciarse con la mayor prontitud sobre su constitucionalidad y validez..$^{8}$

Por el contrario, la Constitución chilena veda al Poder Judicial controlar la situación de emergencia invocada por la autoridad pública para dictar los estados de excepción. En efecto, determina que "los tribunales de justicia no podrán calificar los fundamentos ni las circunstancias de hecho invocados por la autoridad para decretar los estados de excepción". ${ }^{89}$

\subsection{Relación entre la declaración del instituto excepcional y la circunstancia fáctica que le sirve de base}

El texto constitucional de Bolivia prevé una previsión al respecto. Indica que el estado de excepción que se declare debe guardar "estricta relación y proporción con el caso de necesidad atendida por el estado de excepción". ${ }^{90}$

Asimismo, cabe mencionar que la Constitución de Colombia estipula, con relación al estado de guerra exterior o conmoción interior, que los decretos legislativos "solamente podrán referirse a materias que tengan relación directa y específica con la situación que hubiere determinado la declaratoria del Estado de Excepción" ${ }^{91}$ A su vez, se afirma que en el estado de emergencia "podrá el Presidente, con la firma de todos los ministros, dictar decretos con fuerza de ley, destinados exclusivamente a conjurar la crisis y a impedir la extensión de sus efectos"..$^{92}$

La relación de adecuación entre la medida de emergencia adoptada y la cir-

\footnotetext{
86 Constitución de Venezuela, artículo 339.

87 Constitución de Colombia, artículo 215.

88 Constitución de México, artículo 29.

89 Constitución de Chile, artículo 45.

90 Constitución de Bolivia, artículo 138.

91 Constitución de Colombia, artículo 214.

92 Constitución de Colombia, artículo 215.
} 
cunstancia fáctica ha sido también puesta de relieve por la Corte Suprema en su jurisprudencia sobre el control del estado de sitio. Así, el máximo tribunal consideró que no existía relación de adecuación entre la restricción impuesta y las razones que habían motivado la declaración del estado de sitio en los casos Timerman,${ }^{93}$ Spadoni ${ }^{94}$ y Solari Yrigoyen.${ }^{95}$

Esta cuestión está relacionada también con la jurisprudencia emanada del Tribunal Constitucional español relativa a la conexión de sentido en relación con los decretos-leyes. El mencionado tribunal ha indicado que un decreto-ley no puede incluir disposiciones que "por su contenido y de manera evidente, no guarden relación alguna, directa ni indirecta, con la situación que se trata de afrontar" ${ }^{96}$ En efecto, el Tribunal Constitucional español, en una consolidada jurisprudencia, sostiene que debe existir una necesaria conexión entre la situación de urgencia definida y la medida concreta adoptada para subvenir a la misma, ${ }^{97}$ y que el decreto-ley "siempre tendrá que ser la respuesta normativa adecuada congruentemente con la situación de necesidad alegada como título habilitante de la puesta en marcha de esta fuente del Derecho". ${ }^{98}$ Así, el tribunal afirma que necesariamente debe existir una conexión de sentido "en términos de adecuación y congruencia". ${ }^{99}$ Es por ello que el Tribunal Constitucional considera que debe constatar la existencia de una conexión de sentido o relación de adecuación entre la situación definida que constituye el presupuesto habilitante y las medidas que en el decreto-ley se adoptan, de manera que estas últimas guarden una relación directa o de congruencia con la situación que se trata de afrontar". ${ }^{100}$ En este sentido, cabe recordar que, en distintas ocasiones, el Tribunal declaró la inconstitucionalidad de decretos-leyes por entender que no se cumplía con el requisito

93 Corte Suprema de Justicia de la Nación, Timerman, Jacobo, 20/7/1978, Fallos: 300:816.

94 Corte Suprema de Justicia de la Nación, Spadoni, Horacio Ernesto, 8/3/1983, Fallos: 305:204.

95 Corte Suprema de Justicia de la Nación, Solari Yrigoyen, Hipólito s/hábeas corpus, 11/3/1983, Fallos: 305:269.

96 Sentencia del Tribunal Constitucional, 29/1982, del 31 de mayo, Fundamento Jurídico 3.

97 Sentencia del Tribunal Constitucional, 29/1982, del 31 de mayo, Fundamento Jurídico 3; 182/1997, del 20 de octubre, Fundamento Jurídico 3; 137/2003, del 3 de julio, Fundamento Jurídico 4; 68/2007, del 28 de marzo, Fundamento Jurídico 7; 29/2015, del 19 de febrero, Fundamento Jurídico 3; y 48/2015, del 5 de marzo, Fundamento Jurídico 5.

98 Sentencia del Tribunal Constitucional, 6/1983, del 4 de febrero, Fundamento Jurídico 5 in fine.

99 Sentencia del Tribunal Constitucional, 137/2011, del 15 de septiembre, Fundamento Jurídico 5.

100 Sentencia del Tribunal Constitucional, 96/2014, del 12 de junio, Fundamento Jurídico 5; y 27/2015, del 19 de febrero, Fundamento Jurídico 3. 
de la conexión de sentido entre la medida adoptada y la situación de urgencia que se pretendía atender. ${ }^{101}$

\subsection{Rendición de cuentas y responsabilidad ulterior por inexistencia de la situación excepcional por la cual se dictó un instituto de excepción}

La Constitución de Bolivia prevé que, una vez finalizado el estado de excepción, según lo estipula el artículo 139.I, el Ejecutivo debe rendir cuentas a la Asamblea Legislativa Plurinacional "de los motivos que dieron lugar a la declaración del estado de excepción, así como del uso que haya hecho de las facultades conferidas por la Constitución y la ley". ${ }^{102}$

Por su parte, la Constitución colombiana establece la responsabilidad del presidente y de los ministros "cuando declaren el Estado de Emergencia sin haberse presentado alguna de las circunstancias previstas", es decir, en caso de que no hayan sobrevenido hechos que "perturben o amenacen perturbar en forma grave e inminente el orden económico, social y ecológico del país, o que constituyan grave calamidad pública”.

\section{Conclusiones}

Agamben (2003, p. 25) señala que, en el siglo XX, la creación voluntaria de un estado de emergencia permanente devino en una de las prácticas esenciales de los Estados contemporáneos, aun de aquellos llamados "democráticos". Para evitar estos abusos, creo que es necesario que las prescripciones constitucionales acerca de los institutos de excepción sean lo más detalladas posible, a los efectos de establecer directrices claras sobre el modo en que los poderes públicos deben ejercer las facultades excepcionales. En este sentido, Holmes (2004) hace una comparación muy clara respecto a las decisiones adoptadas durante emergencias con los protocolos que siguen los médicos en situaciones de emergencia. Pone de relieve que estos últimos, aun cuando una vida está en juego, siguen estrictos protocolos de cómo actuar; su aplicación lleva tiempo, pero evitan caer en equivocaciones. Del mismo modo, destaca la importancia

101 Sentencia del Tribunal Constitucional, 31/2011, del 17 de marzo; 1/2012, del 13 de enero; 26/2016, del 18 de febrero. Ver también la Sentencia del Tribunal Constitucional 182/1997, del 28 de octubre, voto particular del magistrado Vicente Gimeno Sendra; y 11/2002, del 17 de enero, voto particular del magistrado Pablo García Manzano.

102 Constitución de Bolivia, artículo 139.I. 
de que, aun en emergencia, existan reglas y procedimientos claros, pues las reglas no funcionan siempre y exclusivamente como restricciones que inhabilitan, sino que pueden servir como pautas estables que permiten enfocarse en el propósito, recordar los objetivos a largo plazo y los peligros colaterales que, de otro modo, podrían pasar desapercibidos en una crisis urgente (Holmes, 2004, pp. 303-304).

A su vez, entiendo que si bien muchas veces, como lo ha expresado la Corte Suprema, el carácter temporal que caracteriza a la emergencia "no puede ser fijada de antemano en un número preciso de años o de meses, sino que la emergencia dura todo el tiempo que duran las causas que la han originado", ${ }^{103}$ el establecimiento de plazos precisos en los que los poderes públicos pueden ejercer facultades excepcionales facilitará un mejor control jurisdiccional sobre la cuestión. Como señalé, téngase presente que la delegación es admitida en nuestro país siempre que contenga un plazo, sin precisar con exactitud la duración de esta, lo que ha llevado a delegaciones que han durado varios lustros.

Por otro lado, considero que son muy acertadas las prescripciones constitucionales que requieren que se deba motivar respecto a la existencia de la circunstancia fáctica excepcional. Esto también posibilitará un control jurisdiccional más adecuado sobre la cuestión. Recurrir a fórmulas como las que refieren -que una situación es un hecho de público y notorio conocimientono permite conocer las verdaderas causas que habilitan la declaración de un instituto de excepción. Tener certeza sobre esos hechos facilita el control sobre la relación de adecuación de la situación que se busca conjurar y las concretas medidas adoptadas.

Finalmente, atento a los excesos en los que se suelen incurrir en la utilización de los institutos de excepción, creo que hay que admitir el control jurisdiccional sobre las medidas adoptadas. Es cierto que al Poder Ejecutivo y/o al Poder Legislativo les corresponde declarar la emergencia, y estos tienen mejor información respecto a la cuestión. Si bien, como se analizó, los órganos jurisdiccionales suelen ser deferentes a las medidas que adoptan los poderes públicos para enfrentar las crisis, es importante que se aseguren mecanismos para que estas sean pasibles de un adecuado y equilibrado control jurisdiccional que permita revisar la existencia de la circunstancia fáctica excepcional y, en definitiva, su constitucionalidad.

103 Corte Suprema de Justicia de la Nación, Nadur, Amar c/Borelli Francisco, 15/5/1959, Fallos: 243:449. 


\section{Bibliografía}

Agamben, G. (2003). Estado de excepción. Buenos Aires: Adriana Hidalgo Editora.

Álvarez García, V. (1996). El concepto de necesidad en derecho público. Madrid: Civitas.

Aragón Reyes, M. (2016). Uso y abuso del decreto-ley: una propuesta de reinterpretación constitucional. Madrid: Iustel.

Belknap, M. R. (1980). The Supreme Court Goes to War: The Meaning and Implications of the Nazi Saboteur Case. Military Law Review, (89), 59-95.

Belknap, M. R. (1983). The New Deal and the Emergency Powers Doctrine. Texas Law Review, 62, 67-109.

Bianchi, A. B. (1990). La delegación legislativa. Buenos Aires: Ábaco.

Bianchi, A. B. (1991). La Corte Suprema ha establecido su tesis oficial sobre la emergencia económica. La Ley, t. 1991-C, 141-171.

Bidart Campos, G. (1995). Tratado Elemental de Derecho Constitucional Argentino (Tomo I). Buenos Aires: Ediar.

Bidart Campos, G. J. (2000). Manual de la Constitución Reformada (Tomo II). Buenos Aires: Ediar.

Bin, R. y Pitruzzella, G. (2009). Diritto Constitutzionale (10ª ed.). Torino: G. Giappichelli Editore.

Carmona Contreras, A. M. (1997). La configuración constitucional del decreto-ley. Madrid: Centro de Estudios Políticos y Constitucionales.

Castro E Camargo, M. A. (2011). Decretos-leyes y jurisdicción constitucional. Estudios comparados. Salamanca: Ediciones Universidad de Salamanca.

Castro Videla, S. M. y Maqueda Fourcade, S. (2017). La delegación legislativa y el Estado regulatorio: una mirada crítica al agujero negro de la regulación. Buenos Aires: Ábaco.

Celotto, A. (2002). Parlamento y poderes legislativos del gobierno en Italia: el abuso del Decreto de Urgencia (Decreto ley). Derecho PUCP: Revista de la Facultad de Derecho, (55), 75-94.

Chemerinsky, E. (2015). Constitutional Constitutional Law. Principles and Policies (5ª ed.). Nueva York: Wolters Kluwer.

Cruz Villalón, P. (1984). Estados excepcionales y suspensión de garantías. Madrid: Tecnos.

Dalla Vía, A. R. (2002). El problema de la naturaleza jurídica de la emergencia. Revista Argentina del Régimen de la Administración Pública, 283, 37-45.

Dalla Vía, A. R. (2006). Derecho constitucional económico. Buenos Aires: Abeledo Perrot.

De Otto, I. (1988). Derecho Constitucional. Sistema de Fuentes (2 ed.). Barcelona: Ariel.

De Vergottini, G. (2010). Diritto Constitutzionale (7ª ed.). Padua: Cedam.

Dulitzky, A. E. (2004). Alcance de las obligaciones internacionales de los Derechos Humanos. En Martin, C., Rodríguez Pinzón, D. y Guevara B., J. A. (Comps.), Derecho Internacional de los Derechos Humanos (pp. 79-117). Ciudad de México: Universidad Iberoamericana.

Ekmekdjian, M. A. (2008). Manual de la Constitución Argentina (6 ${ }^{\mathrm{a}}$ ed.). Buenos Aires: Lexis Nexis.

Elias, J. S. (21 de diciembre de 2010). Urgencia, necesidad y decretos. La Ley. Suplemento Universidad de San Andrés, (7).

Elias, J. S. (2013). Leyes de emergencia económica y control judicial de constitucionalidad: radiografía de una relación difícil. Revista de Teoría del Derecho de la Universidad de Palermo, II(1), 115-156. 
Fallon Jr., R. H. (2013). The dynamic constitution: an introduction to American constitutional law and practice ( $2^{\mathrm{a}}$ ed.). Cambridge: Cambridge University.

Field, O. P. (1999). The effect of an unconstitutional statute. Washington, D. C.: Beard Books.

Frosini, T. E. (2006). El estado de derecho se ha detenido en Guantánamo. Revista española de derecho constitucional, 26(76), 33-74.

García Macho, R. y Sommermann, K. P. (Trad.). (2010), Ley Fundamental de la República Federal de Alemania. Berlín: Deutscher Bundestag.

García Pelayo, M. (1999). Derecho Constitucional Comparado. Madrid: Alianza.

Gargarella, R. (1996). La justicia frente al gobierno. Sobre el carácter contramayoritario del poder judicial. Barcelona: Ariel.

Garrorena Morales, A. (2014). Derecho Constitucional. Teoría de la Constitución y sistema de fuentes ( $3^{\text {a }}$ ed.). Madrid: Centro de Estudios Políticos y Constitucionales.

Gelli, M. A. (2008). Constitución de la Nación argentina. Comentada y concordada (Tomo I, 4a ed.). Buenos Aires: La Ley.

Gros Espiell, H. (1991). La Convención Americana y la Convención Europea de Derechos Humanos. Análisis comparativo. Santiago de Chile: Editorial Jurídica de Chile.

Gross, O. y Ní Aoláin, F. (2006). Law in times of crisis: emergency powers in theory and practice. Cambridge: Cambridge University Press.

Jakab, A. (2006). German Constitutional Law and Doctrine on State of Emergency - Paradigms and Dilemmas of a Traditional (Continental) Discourse. German Law Journal, 7(5), 460-464.

Hauriou, A. (1980). Derecho Constitucional e instituciones políticas (2a ed.). Madrid: Ariel.

Holmes, S. (2004). In Case of Emergency: Misunderstanding Tradeoffs in the War on Terror. California Law Review, 97(2), 301-355.

León Zaa, J. C. (2014). El estado de excepción en el constitucionalismo andino: especial consideración de Chile y Perú. (Tesis doctoral). http://eprints.ucm.es/24605/1/T35116.pdf.

Lobel, J. (1989). Emergency Power and the Decline of Liberalism. Yale Law Journal, 98, 1385 1433.

Loianno, A. (2005). Estado de sitio y derechos humanos: la excepcionalidad de la emergencia. En Sabsay, D. A. (Dir.), Colección de Análisis Jurisprudencial Derecho Constitucional (pp. 609. 632). Buenos Aires: La Ley.

Lorenzetti, R. L. (2003). Nunca más: Emergencia económica y derechos humanos. La Ley, t. 2003-A, 1207-1221.

Martínez Cuevas, M. D. (2002). La suspensión individual de derechos y libertades fundamentales en el ordenamiento constitucional español: un instrumento de defensa de la Constitución de 1978. Granada: Comares.

Midón, M. A. R. (2012). Decretos de necesidad y urgencia: en la Constitución Nacional y en los ordenamientos provinciales (2 $2^{\mathrm{a}}$ ed.). Buenos Aires: Hammurabi.

Nino, C. S. (2005). Fundamentos de Derecho Constitucional. Buenos Aires: Astrea.

Ortiz Gutiérrez, J. C. (2017). El presidencialismo colombiano. En García Belaunde, D. et al., El presidencialismo latinoamericano y sus claroscuros (1ª ed.) (pp. 167-223). Cochabamba: Kipus.

Padilla, M. M. (2002). El control judicial de las declaraciones de emergencia. Revista Argentina del Régimen de la Administración Pública, 283, 31-35.

Pérez Pérez, A. (1999). Los sistemas constitucionales de Alemania y Uruguay frente a situacio- 
nes de excepción. En Demasi, C., Pérez Pérez, A., Rico, A., Schneider, H. y Sontheimer, M., Estado de derecho y estado de excepción. Alemania y Uruguay: las décadas violentas (pp. 121-135). Montevideo: Trilce.

Posner, R. A. (2006). Not a Suicide Pact: The Constitution in a Time of National Emergency. Oxford: Oxford University Press.

Posner, R. A. y Vermeule, A. (2007). Terror in the balance: security, liberty, and the courts. Oxford: Oxford University Press.

Rehnquist, W. H. (1987). The Supreme Court, how it was, how it is. Nueva York: William Morrow and Co. Inc.

Relyea, H. (1974). A Brief History of Emergency Powers in the United States. Washington: US Goverment Printing Office.

Roots, R. I. (2000). Goverment by Permanent Emergency: The forgotten History of the New Deal Constitution. Suffolk University Law Review, 33, 259-296.

Rossiter, C. L. (1948). Constitutional Dictatorship. Crisis Government in the Modern Democracies. Princeton: Princeton University Press.

Sabsay, D. A., (2010). DNU e inconstitucionalidad de la ley 26.122. La Ley Online, La Ley, AR/ DOC/930/2010, 1-3.

Sacristán, E. B. (2014). Control judicial del estado de sitio y de la intervención federal. Revista de Investigações Constitucionais, 1(1), 39-66.

Sagüés, N. P. (1990). Derecho Constitucional y derecho de la Emergencia. La Ley, t. 1990-D, 1036.

Sagüés, N. P. (2003). La declaración del estado de emergencia económica por el derecho nacional y el transnacional. Revista Iberoamericana de Derecho Constitucional, 2003(1), 113-117.

Sagüés, N. P. (2016). Constitución bajo tensión. México: Instituto de Estudios Constitucionales del Estado de Querétaro.

Santiago (h.), A. y Thury Cornejo, V. (2003). Tratado sobre la delegación legislativa. Buenos Aires: Ábaco.

Scheppele, K. L. (2006). North American emergencies: The use of emergency powers in Canada and the United States. International Journal of Constitutional Law, 4(1), 213-243.

Schneider, H. P. (1999). Problemas de la Constitución de emergencia y de la legislación de emergencia a la luz de la ley fundamental. En Demasi, C., Pérez Pérez, A., Rico, A., Schneider, H. y Sontheimer, M., Estado de derecho y estado de excepción. Alemania y Uruguay: las décadas violentas (pp. 101-120). Montevideo: Trilce.

Sunstein, C. R. (1987). Constitutionalism after the New Deal. Harvard Law Review, 101, 421. 510.

Swaine, E. T. (2010). The Political Economy of Youngstown. Southern California Law Review, 83, 263-339.

Tribe, L. H. (1988). American Constitutional Law (2a ed.). Nueva York: The Foundation Press, Inc.

Úbeda de Torres, A. (2007). Democracia y Derechos Humanos en Europa y América. Estudio comparado de los sistemas europeo e interamericano de protección de los derechos humanos. Madrid: Reus.

Vanossi, J. R. (2003). El mar no perdona. La Ley, t. 2003-C, 950-959.

Vermeule, A. (2008). Holmes on Emergencies. Stanford Law Review, 61, 163-202. 
Ylarri, J. S. (2016). Emergencia económica (a la luz del caso argentino). Eunomía. Revista en Cultura de la Legalidad, (10), 179-190.

Ylarri, J. S. (2019a). La emergencia económica. El control de constitucionalidad de la situación de emergencia económica y su declaración normativa. Buenos Aires: Ábaco.

Ylarri, J. S. (2019b). Los decretos-leyes y el control de la "extraordinaria y urgente necesidad". Buenos Aires: Lajouane.

Ylarri, J. S. (2020). Los alcances del control judicial sobre las normas adoptadas para enfrentar el Coronavirus. En Falke, I. (Dir.), La Tutela de la Salud Pública. El Derecho Procesal en Épocas del Coronavirus. Buenos Aires: IJ Editores. 
